\title{
The Effects of Dual-Credit Enrollment on Underrepresented Students: The Utah Case
}

\author{
Richard E. Haskell ${ }^{1}$ \\ ${ }^{1}$ Bill and Vieve Gore School of Business, Westminster College, Salt Lake City, Utah, USA \\ Correspondence: Richard E. Haskell, Sr., PhD, Bill and Vieve Gore School of Business, Westminster College, \\ Salt Lake City, Utah, USA. Tel: 1-801-832-2600. E-mail: rhaskell@ westminstercollege.edu
}

Received: October 13, 2015

Accepted: October 28, 2015

Online Published: December 25, 2015

doi:10.5539/ijef.v8n1p144

URL: http://dx.doi.org/10.5539/ijef.v8n1p144

\begin{abstract}
This study considers the effects of Utah's Dual-Credit Enrollment (DCE) and Early College High School (ECHS) programs on underrepresented students' performance via an examination of the Utah Data Alliance longitudinal public education dataset. The study assesses standardized testing scores, high school graduation rates, dual course credits earned, higher education enrollment, time-to-completion, and degree attainment outcomes for various minority and low income student groups enrolled in DCE and ECHS programs.

To limit the endogeneity and self-selection bias present in non-experimental data, the study employs Propensity Score Matching method (PMS) as a quasi-experimental design methodology. Although PMS offers many advantages, its strength as an estimator is dependent on the existence of complete and quality matching variables. To assure accurate model specifications given the available data, Receiving Operator Characteristic (ROC) Analysis is applied to variations on the PMS models.

Estimated outcomes reflect positive effects for each of the examined student populations differentiated by gender, race, income and English Language Learner status. The economic effects of accumulating higher education course credits and decreases in higher education time-to-completion may yield the most interesting outcomes, enjoy the strongest causal claims, and result in measurable household and state level savings. These outcomes may also reveal potential weakness in the structure of higher education course and major programming, and the difficulty presented as high school students make higher education decisions.
\end{abstract}

Keywords: dual credit enrollment, concurrent enrollment, public education, Utah, early college high school, propensity score matching, receiving operating characteristics, underrepresented

\section{Introduction}

The rising cost of human capital inputs, coupled with growing national interest in fiscal responsibility and widening relative socio-economic distributional inequalities, renders the need for innovative solutions in support of efficient and improving outcomes. As such, the focus of this study is to examine the effects of two particular innovations in secondary education, Dual-Credit Enrollment (DCE) and Early College High School (ECHS), with specific focus given to their relative effects on underrepresented student populations.

Dual-credit enrollment (Note 1) programs have become widely popular in the United States (Berger et al., 2013; Edmunds et al., 2010; Kleiner \& Lewis, 2005; Martinez \& Bray, 2002). These programs allow public high school students to enroll in challenging college level courses via concurrent enrollment, early enrollment or advanced placement, providing course credit for both high school and higher education. Though there are variations from state to state, these programs allow secondary education students to accumulate higher education credits while simultaneously fulfilling public high school graduation requirements (Bailey \& Karp, 2003; Boswell, 2001; Greenberg, 1988). Such programs have proven effective in easing the transition between high school and college generally and may motivate improvements in secondary and higher education outcomes (Harnish, 2005; Vargas, 2013). In most areas participation relies on self-selection, though the benefits of participation are observable, statistically significant, and positive (Swanson, 2008; Taylor, 2013). State level policy directives specify the targeting of underrepresented students for such programs in an effort to narrow the observable and growing education gap contributing to troublesome differences in productivity, income, health and wealth for these students and their current and future households (Bailey, 2007; Bragg, Kim, \& Rubin, 2005; Kirst, \& Venezia, 2006; 
Hoffman, 2003; McKinsey \& Co., 2009).

DCE differs from ECHS in that DCE is motivated by a student's choice to participate in dual-credit courses while attending their traditional high school, often referred to as the student's boundary school. ECHS participants attend public high school without respect to district or school-level boundaries in a facility dedicated to maximizing dual-credit course enrollment, often located on or near a public higher education campus. ECHS offers a structure through which students are focused towards earning a substantial number of higher education credits while in high school, often sufficient to earn an Associate's Degree, rather than earning a limited range of higher education credits. Wherever possible, high school courses required for graduation are substituted with concurrent enrollment, early enrollment and advanced placement courses taught at the high school or affiliated college. Where ECHS students choose to earn an Associate's degree coincident with receiving their high school diplomas, several additional college level courses are required. Depending on the student's preferred course selection, these courses may be taken at the ECHS as additional concurrent enrollment courses, while others may be taken as early enrollment at the affiliated college. Both DCE and ECHS programs provide a head start towards college completion at the expense of the state's public education system and without greater burdens on that system or those households supporting it (Fincher-Ford, 1996; Karp \& Hughes, 2008; Lieberman, 2004; Welsh et al., 2005).

Until recently, Utah's relatively homogenous households have led to an equally homogenous workforce dominated by a well-educated Caucasian majority. However, changes in the state's socio-economic structure resulting from increased labor mobility, immigration, and declining domestic household birthrates yield substantial increases in underrepresented (Note 2) student populations (Alliance for Excellent Education, 2009 \& 2012). Absent thoughtful intervention, these changes may result in widening relative socio-economic status and productivity levels. Like the United States, Utah has traditionally enjoyed such educational output as to place it amongst the top of its peer group, but that position has eroded in recent decades such that improvements are called for from both the public and private sectors (US Department of Education, 2008). The formation of the Utah Education Policy Center (Note 3) and Utah Data Alliance (Note 4), funded through the American Recovery and Reinvestment Act of 2009 and the Utah Legislature (2014 (Note 5)), have facilitated the compilation of a longitudinal data set of Utah public education data sufficiently rich to examine the effects of DCE and ECHS on targeted secondary and higher education outcomes. The data includes individual level student data from the Utah State Office of Education, Utah System of Higher Education, Utah College of Applied Technology and Utah Department of Workforce Services inclusive of public education enrollment, performance, and completion data, and limited demographic, labor market and income data. This study represents the first examination of this data set by a researcher outside of the UDA and its stakeholders.

Numerous studies support positive outcomes for participants in DCE and ECHS programs (Karp et al., 2007; Kim \& Bragg, 2008; Speroni, 2011; Struhl \& Vargas, 2012; Swanson, 2008), but few employ statistical methods sufficient to infer causality and to estimate their effects (An, 2009; Speroni, 2011; Struhl \& Vargas, 2012; Taylor, 2013). Propensity Score matching (PSM) is employed in this study to measure DCE and ECHS's effects on selected outcomes as the method provides a methodologically sound alternative to linear regression modeling applicable to social science research (Austin, 2011; Dehejia \& Wahba, 2002; Peikes, Moreno, \& Orzol, 2012; Rosenbaum \& Rubin, 1983, 1984, \& 1985). To assure the accuracy of the selected models, receiver operating characteristic (ROC) analysis is employed as a post estimation tool.

This study includes available demographic and public education enrollment and performance data for Utah's public high school graduation cohorts of 2008 and 2009 and considers the effects of participation in DCE and ECHS programs as treatments on subject student populations. These effects are estimated for secondary education performance (ACT scores) and graduation, dual course credits earned (Note 6), post-secondary higher education enrollment, and higher education time-to-completion and degree attainment outcomes. Traditional high school students (TRAD) are used as the control, or non-treated, group. PSM and ROC analytics are employed to estimate the average effects of these treatments on the treated, from which a discussion of potential economic and social impacts leads to the consideration of public policy issues and their resulting household endowments.

\section{Dual-Credit Enrollment and Early College High School Programs in Utah}

Though high by national standards, the 2008 and 2009 Utah public high school graduates included $88 \%$ of those expected (USOE, 2013), a figure which, though improving since 2000, had been relatively constant for too long (Heckman \& LaFontaine, 2010). State-level data with respect to income and minority status reflects Utah's minority population performing poorly compared to national figures, with the greatest differentials represented for Hispanic and Asian students; Utah's most rapidly growing student populations (Alliance for Excellent Education, 2011). In 2009 more than 10,500 Utah high school students failed to graduate with their peers, representing 
lost-lifetime earnings of more than $\$ 2.7$ billion (Alliance for Excellent Education, 2009). Though the state's minority populations have shown greater improvement in graduation rates than those of Caucasians in recent years, they continue to lag behind the general student population. Hispanic students have shown the strongest rate of improvement in the years 2008-2013 (16\%), followed by that of the American Indian and Black populations (13\% each); each remaining well below that of the Caucasian student population by $17 \%$ and $20 \%$ respectively (USOE, 2013).

In an effort to improve worker productivity and incomes generally, and to specifically thwart the problem represented by the growing skills gap among US workers, states have begun to adopt initiatives focused on improving outcomes and better preparing their workforces. Utah's effort includes a variety of innovative programs intended to improve high school and higher education outcomes, including the Utah System of Higher Education's 15 to Finish (Note 7) campaign and a public/private initiative titled Prosperity 2020 (Note 8). Each initiative is complemented by increasingly rigorous high school education options such as those provided through DCE and ECHS programs.

In partial fulfillment of state-level goals, the Utah State Office of Education and Utah System of Higher Education actively encouraged and supported the development of Utah's six early college high schools (Note 9) with the express purpose of serving underrepresented students. In 2012 Utah's Early College High Schools graduated 781 students out of 32,884 high school graduates throughout the state (USOE, 2013), barely 2.3\% of the cohort. These schools enjoyed a dropout rate of less than $2 \%$ compared to a state dropout rate of $12 \%$ for the year, and a dropout rate of over $7 \%$ for the state's other dual-credit enrollment students (USOE, 2013).

Dual-credit enrollment programs in Utah are required to follow guidelines established by the Utah State Legislature inclusive of the program's purpose, student eligibility, school and student participation, credit transfer, the program's fiscal attributes. Utah's express purpose for offering dual-credit courses is to "provide a challenging college-level and productive secondary school experience, particularly in the senior year, and to provide transition courses that can be applied to post- secondary education" (UAR R277-713, p. 2). Like most states, Utah includes eligibility standards for dual-credit participation consistent with those of the higher education institution offerings the course(s).

Students selecting participation in Utah ECHS apply for a limited number of openings each year with acceptance based on interviews and completion of an entrance examination, the requirements for which are no different than those required for advancing from one grade to another in the broader Utah secondary education environment; the charters for each of these schools specifies preference to be extended underrepresented students (Note 10). Utah's ECHS students receive per pupil funding from state and federal sources at the same levels as their traditional public high school counterparts, require no additional individual or household contributions, and higher education tuition for the credit hours earned is paid out of the school's allocated state and federal funds (UAR R277-713, p. 3).

\section{Utah Public High School and Higher Education Students (Note 11)}

Utah's public education high school graduation cohorts of 2008 and 2009 include 45,214 and 45,328 students respectively. Of the 90,642 students in the combined cohorts, $65.2 \%$ received a high school diploma in the prescribed time frame. This differs from the $88 \%$ graduation rate for 2008 and 2009 published by the state as the data compiled in the Utah Education Longitudinal data set complies with the US Department of Education's cohort graduation requirements, rather than the state's more generalized and often cited graduation rate (USOE 2013). Of the combined cohorts, $52 \%$ are male, $48 \%$ female, $21 \%$ minority, $41 \%$ low income, and $12 \%$ English Language Learners. Low-income male and female students, $21 \%$ and $20 \%$ respectively, accounted for 37,127 students. While minority male and female students represented $11 \%$ and $10 \%$, totaling 18,978 students (Figure 1). The distributions change when differentiated by treatment with participation in ECHS representing just $1.1 \%$ of the combined high school graduation cohorts and DCE representing $36.7 \%$. 


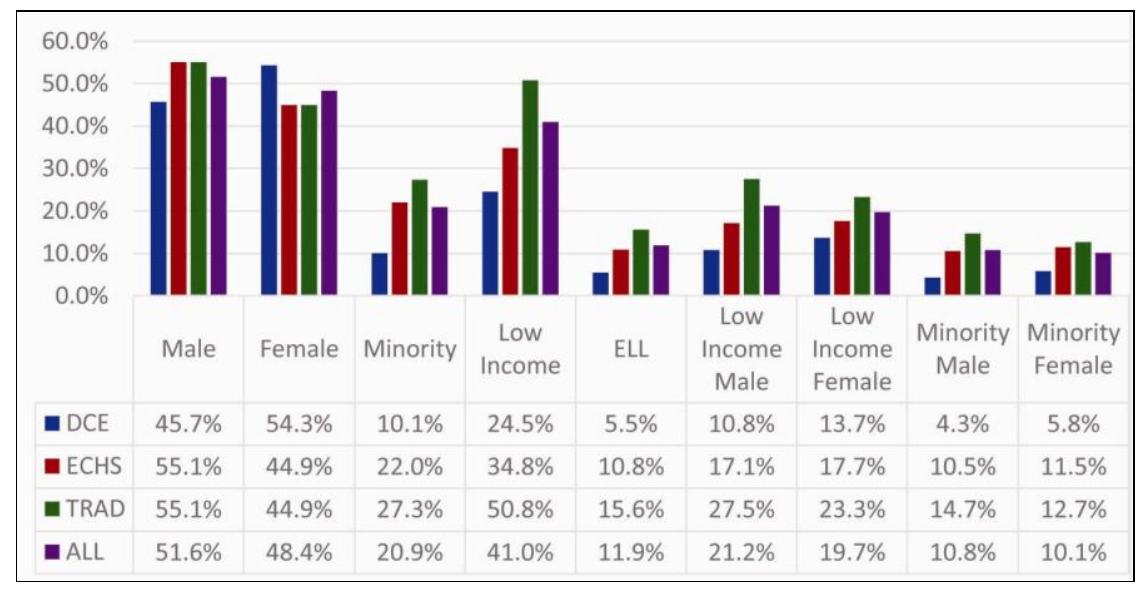

Figure 1. Socio-economic status by treatment

Though dual credit programs are expected to be targeted to underrepresented students, program participation differentiated by socio-economic factors suggests the state has significant work to do as the socio-economic status of ECHS and DCE participants does not mirror that of the high school graduation cohorts from which they come. We see that socio-economic status of the respective cohorts are relatively homogenous, but when DCE and ECHS statistics are compared to the average for the cohorts we see meaningful differences. DCE outcomes include lower male, minority, low income, and English Language Learner (ELL) populations than the average cohort (ALL) and higher female components, while ECHS treatment groups are more reflective of the average. This leaves the traditional (TRAD) students, the control group, with higher male, low income, minority and ELL and lower female representation than the average cohort.

The measures for students taking the ACT exam and high school graduation echo disparities observed across the nation. The ACT exam was taken by 36,189 students, $40 \%$, in the general population while $20 \%, 24 \%$ and $20 \%$ of minority, low income and ELL students sat for and completed the exam (Figure 2).

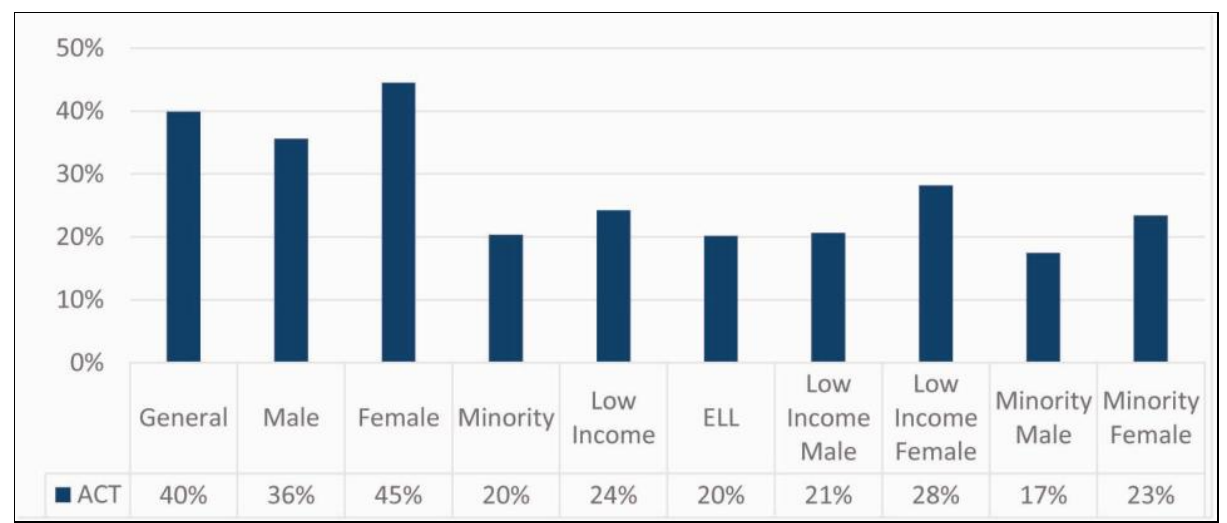

Figure 2. ACT by student group

The measures for dual course credits differ only marginally for minority, low income, and ELL DCE participants with a high of 9.51 and low of 9.15 in the subject student groups, though these levels are lower than those observed in the general student population regardless of gender (Figure 3). Low income DCE participants accumulated slightly more dual course credits than did their minority student group counterparts with minority females accumulating the fewest number of credits at 9.15. ECHS participants accumulate dual course credits at a higher level than do DCE participants, as might be expected. ECHS participants also experienced a wider range of credit accumulation, from a low of 13.61 to a high of 16.16 in the various minority, low income and ELL student groups. Again, those in the subject student groups tend to accumulate fewer credits than their general student polulation peers. Low income males tended to accumulate the highest number of credits at 15.98 with minority students accumulating 13.98 credits. 


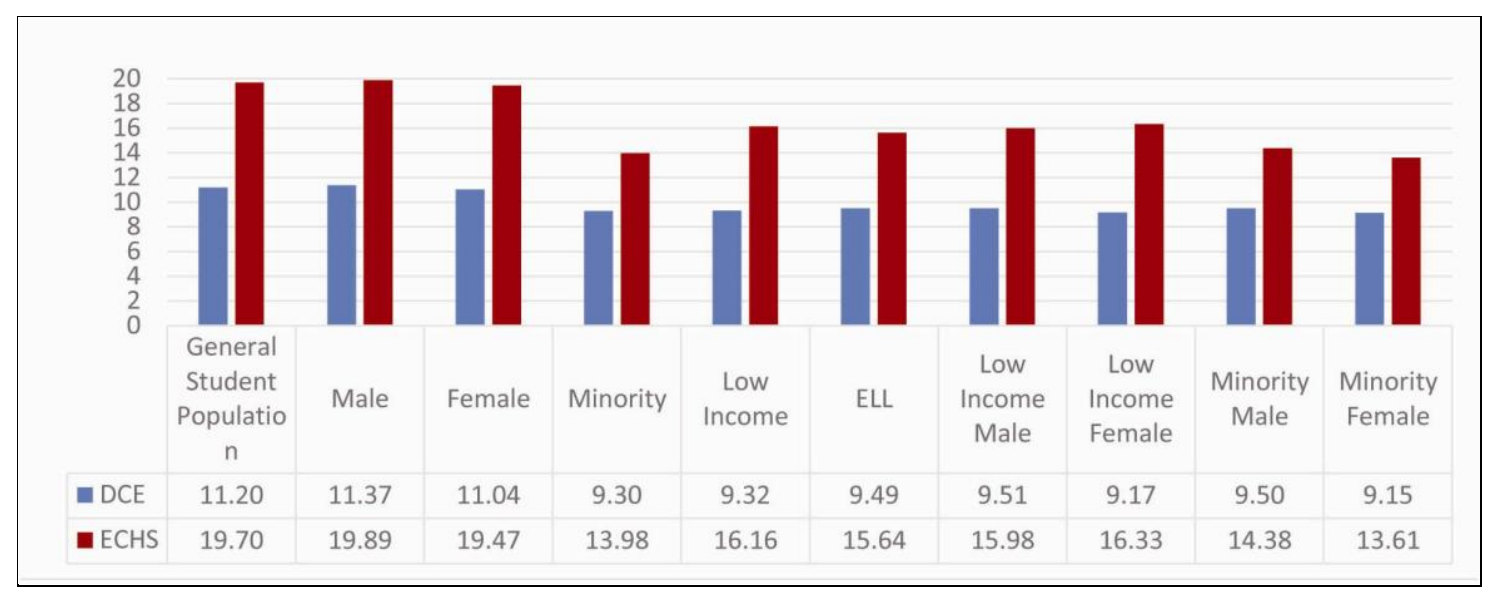

Figure 3. Dual credit hours earned

The conversion ratio for concurrent enrollment credit hours earned versus those attempted suggests an interesting relationship in this study (Figure 4). Unlike the dual course credit meaure, this does not include advanced placement course credits as successful completion of advanced placement courses result in varying levels of higher education credits granted based on the guidelines of the college or university at which the student seeks to apply them. Concurrent and early enrollment course credits in Utah public education are earned as higher education credits from the Utah System of Higher Education (USHE), and provided equal credit at any of Utah's public colleges and universities. DCE participants experience credit conversion at $83.2 \%$ in the general student population, a level equalled by the minority female student populatoin and only minimally different than each of the measured groups. By contrast, ECHS participants in the general student population average $86.2 \%$ concurrent enrollment course credit conversion, a level 6.4\% higher than the lowest underrepresented student group measured.

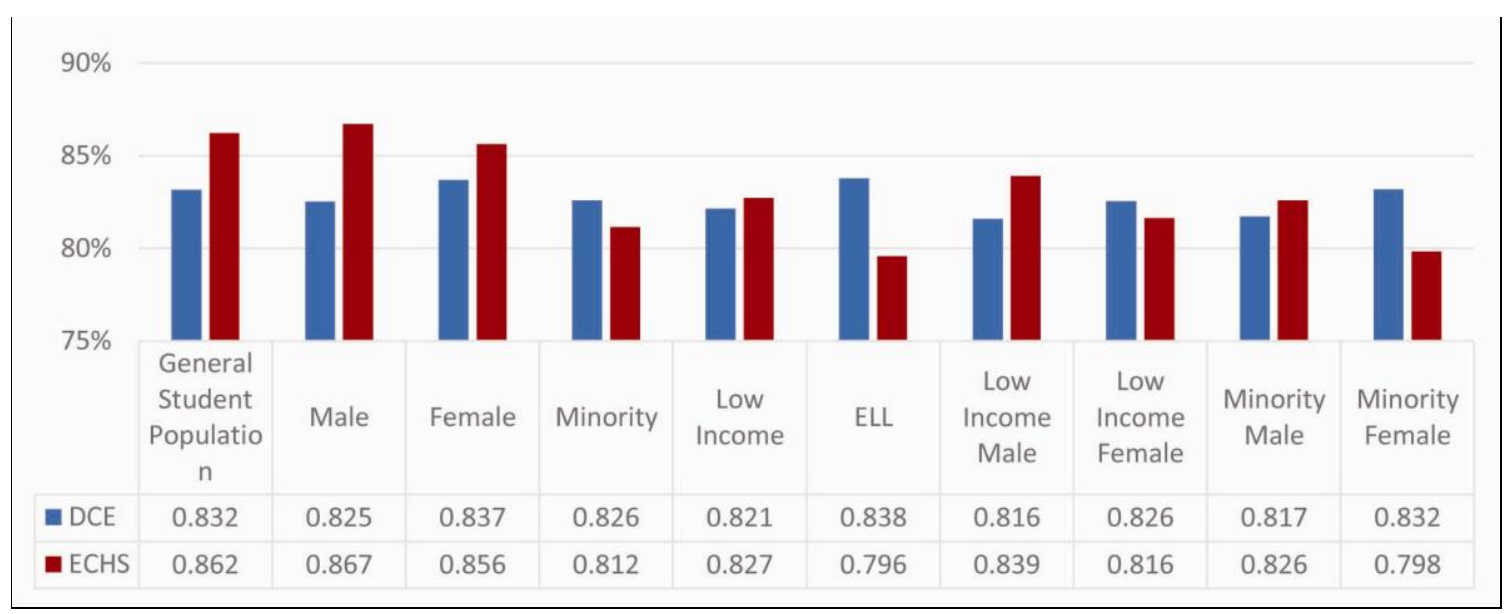

Figure 4. Concurrent enrollment credit hours earned/attempted ratio

While high school enrollment and graduation present near even male/female distribution, low income, minority, and ELL student group graduation rates are sharply lower than those in the general student populations (Figure 5). Where $63 \%$ of males graduated from high school, $48 \%$ and $42 \%$ of low income and minority males graduated. Similar disparities can be seen in the female student population with minority and low income females graduating at sharply lower rates than for females in the general student population. 


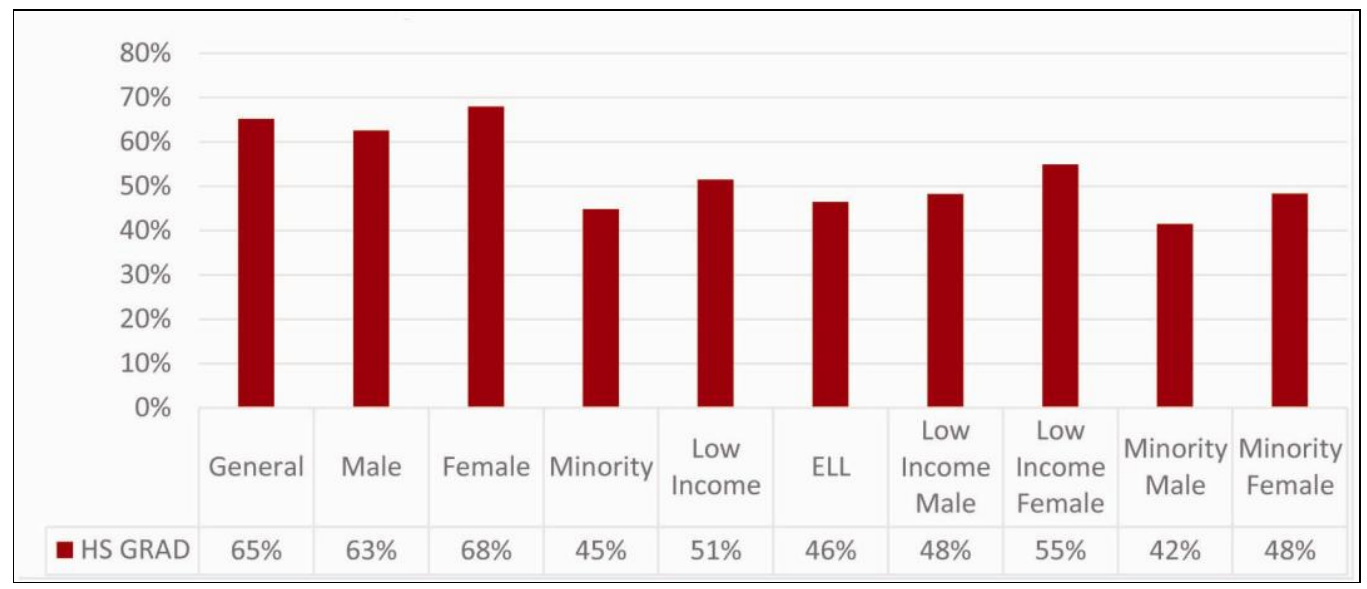

Figure 5. HS graduation by student group

Utah higher education enrollment figures for the subject cohorts show meaningfully lower rates of enrollment for low income and minority student groups for both Utah public higher education as well as higher education generally (Figure 6). English language learners have one of the lowest rates of higher education enrollment, with only $38 \%$ of ELL students enrolling in higher education, and have a dramatically reduced rate of enrollment in Utah public higher education (3\%). Though low income and minority males and females enroll in higher education at a rate roughly $15 \%$ lower than their general population counter parts, their enrollment in Utah public education is otherwise relatively consistent at $8-9 \%$ less than higher education enrollment generally. The gap between higher education enrollments in Utah public education versus higher education generally is heavily influenced by the presence of Brigham Young University, a private institution affiliated with Utah's dominant religious group, the Church of Jesus Christ of Latter-Day Saints (LDS).

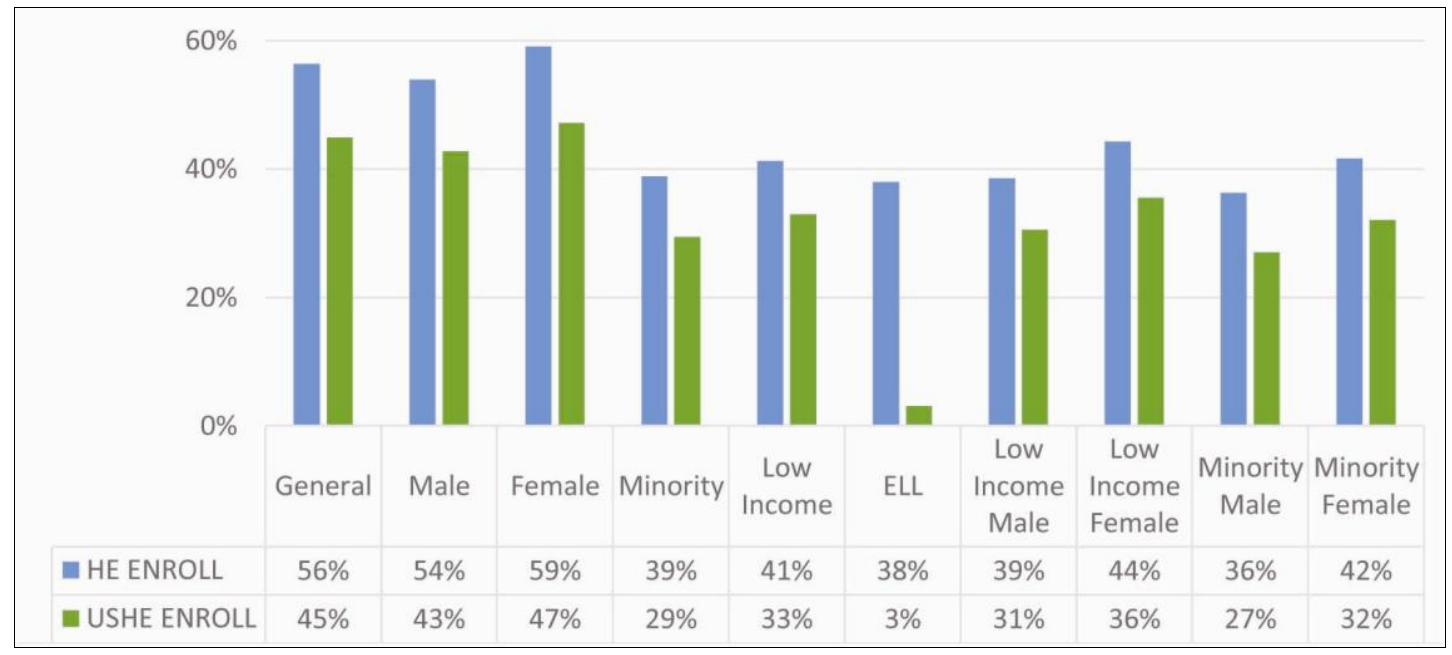

Figure 6. Higher education enrollment : HE \& USHE by student groups

Higher education graduation figures represent the percentage of the respective student groups having completed a higher education degree or certificate program (Figure 7) The data used in this study includes post-secondary higher education through the 2013 academic year update and represents five and four years of higher education data for the 2008 and 2009 cohorts, respectively. Higher education graduation data shows minority and low income graduation levels lower than that of their respective peer groups. Male and female disparities are relatively consistent among student groups, though male graduation rates lagging female rates by as much as $50 \%$, proportionately. This may also be influenced by student religious affiliation as some Utah males in the subject cohorts as a result of the voluntary mission experience many of these males experience with the LDS church (Note 12). 


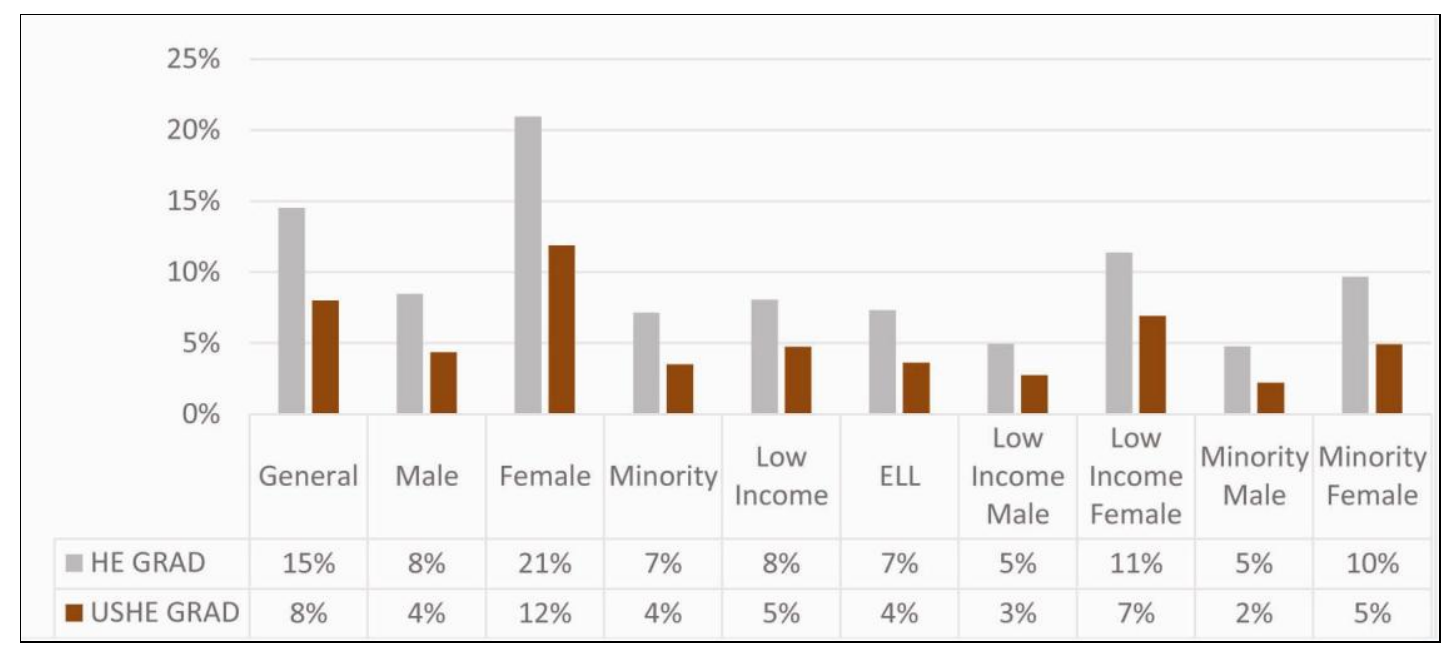

Figure 7. Higher Ed graduation: HE (all) \& USHE by student groups

Measures of higher education degree attainment (Associate and Bachelor's) are calculated as a percentage of those successfully completing a higher education degree. As would be expected given the period for which data is included, Bachelor's degree attainment lags that of an Associate's degree, which difference may change or even be reversed with additional years of higher education participation (Figure 8). The relatively high level of Associate's degree attainment among the cohorts is also influenced by the high number of these degrees earned by ECHS students; 786 of the 6,554 among the subject cohorts.

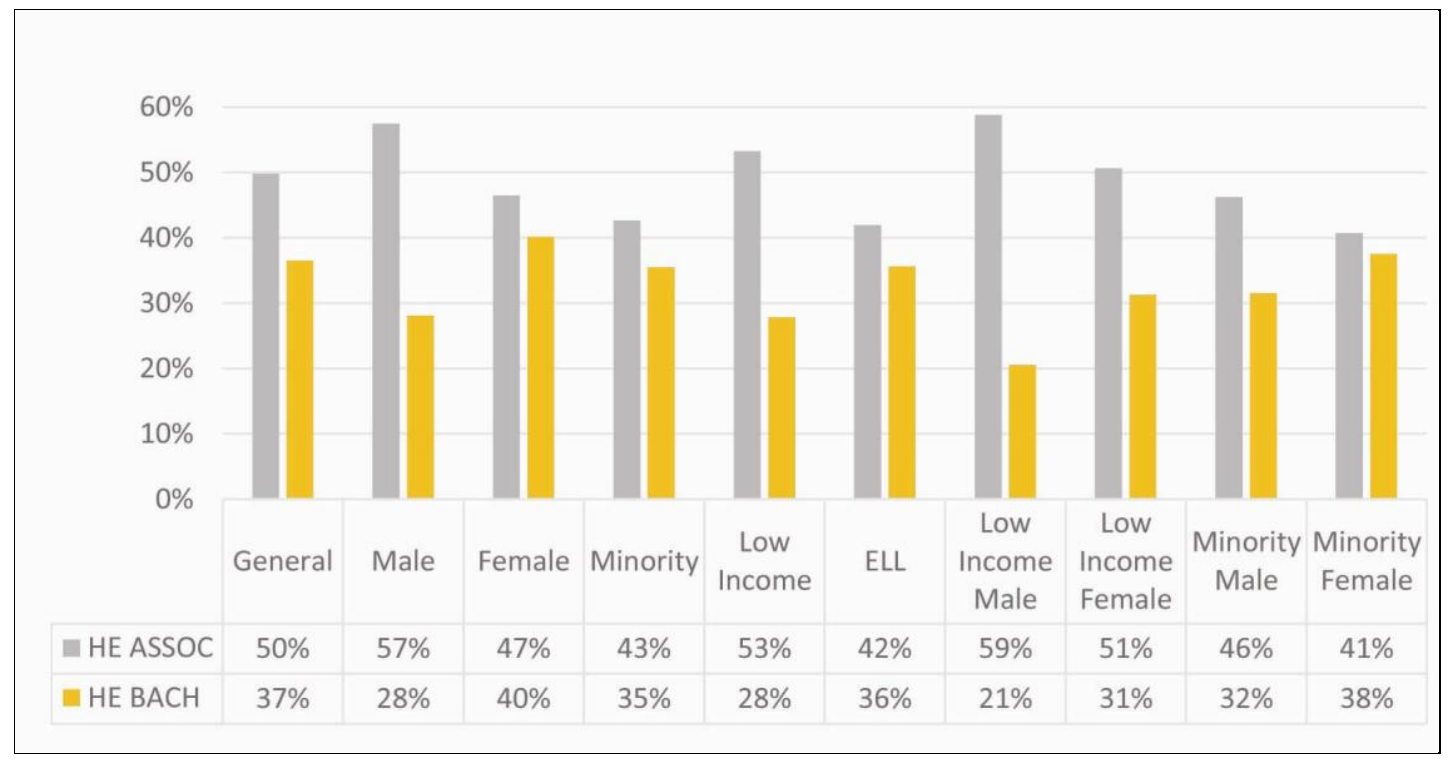

Figure 8 . Higher education degree attainment by student groups

Time-to-completion in this study is measured as the days to degree completion (Associate or Bachelor's) from June $1^{\text {st }}$ of each cohort's high school graduation year. There is little difference among the various student groups for each degree type measured with an average time-to-completion of 947 and 1,549 days for Associate and Bachelor's degrees, respectively, among the various minority and low income student groups. This differs from their respective peers among the general student population by approximately one to two months (Figure 9). 


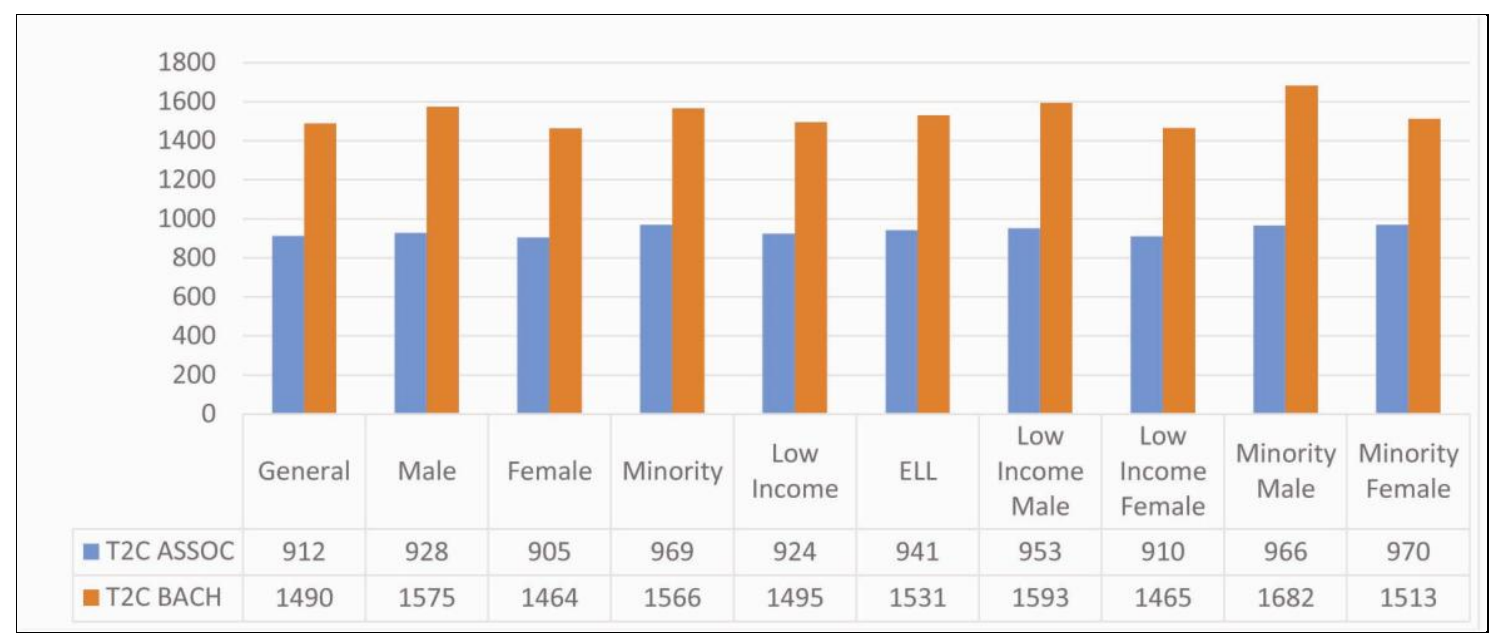

Figure 9. Mean time-to-completion (days) by student groups

\section{Methodology}

To estimate the effects of DCE and ECHS, this study employs Propensity Score Matching (PSM) as an alternative to standard linear regression estimation forms, such as OLS and GLS, in support of assessing causal inference (Abadie \& Imbens, 2012; Dehejia \& Wahba, 2002; Peikes, Moreno \& Orzol, 2012; Rosenbaum \& Rubin, 1983, 1984, \& 1985). PSM is used extensively to support causal inference in education studies, including those related to DCE and ECHS (An, 2009; Schneider et al., 2007; Speroni, 2011; Struhl \& Vargas, 2012; Taylor, 2013). The method provides a quasi-experimental design structure for non-experimental studies in which a prescribed treatment is applied to a portion of the study participants via non-randomized participation resulting in endogeneity or self-selection bias (Eide \& Showalter, 2012). Matching occurs through the selection of available pre-treatment independent variables, such that matched pairs are observable, distinguishable by their treatment selection. The average treatment effects are measured for the sample population and are then compared to the average treatment effect on the treated. When relevant differences between any two units are captured in the observable (pre-treatment) covariates, which occurs when outcomes are independent of assignment to treatments conditional on pretreatment covariates, matching methods can yield an unbiased estimate of the treatment effect. Where treatments are applied via self-selection, or in a non-experimental manner, there is no reasonable way to discern what outcomes may have occurred had the treatment not been applied: the counterfactual (Morgan \& Wanship, 2007).

From a theoretical standpoint, the way to obtain a counterfactual is to use the same participants under both treatment and control conditions, restoring internal and external conditions to initial values present before participants encountered either. As such, participant outcomes are observed under the treatment (factual) and the control condition (counter-factual), and the difference in outcomes is the individual treatment effect. Averaging individual treatment effects for both groups and then subtracting those average from the quantified outcome (observed or estimated) yields the average treatment effect (Murnane \& Willett, 2011, pp. 33-34). However, resetting internal and external conditions isn't feasible in social science research and as such, it is virtually impossible to obtain the outcome value of the control condition for individuals in the treatment group and it similarly lacks feasibility to obtain the outcome value of the treatment for individuals in the control group. Since observing or identifying counterfactual data isn't feasible in social science research there will always be missing data when calculating the average treatment effects (Holland, 1986; Murnane \& Willett, 2011; Shadish, Cook, \& Campbell, 2002).

\subsection{Estimation Models}

PSM analytics are not strictly regression estimates, but use probit or logit forms to compute the propensity score, which are simply probabilities. If the outcome is continuous, the effect of treatment can be estimated as the difference between the mean outcome for treated subjects and the mean outcome for untreated subjects in the matched sample (Rosenbaum \& Rubin, 1983, 1984 \& 1985). If the outcome is binary, the effect of treatment can be estimated as the difference between the proportion of subjects experiencing the event in each of the two groups (treated versus untreated) in the matched sample. As such, the reporting of treatment effects can be done using the same metrics as are commonly used in randomized control treatments. The estimates report with 
coefficient, standard error, $P$ value, and confidence intervals as do regression estimates, but include a calculated $\mathrm{z}$-score rather than a $t$ statistic to aid in inferring statistical significance and do not include an $r$ squared value suggestive of the level of the model's fit.

As this study considers several potential outcomes for each of two Utah public high school graduation cohorts and separately examines the effects of two unique and one combined treatment on each, the organization of the estimation models is relatively complex, even though the models themselves appear to be as simple as $Y=\beta_{1}$ treatment $+e$. This model is estimated for each match in the covariate set and it is only then that a coefficient, standard deviation, z-score, probability, and confidence intervals are determined (Figure 10).

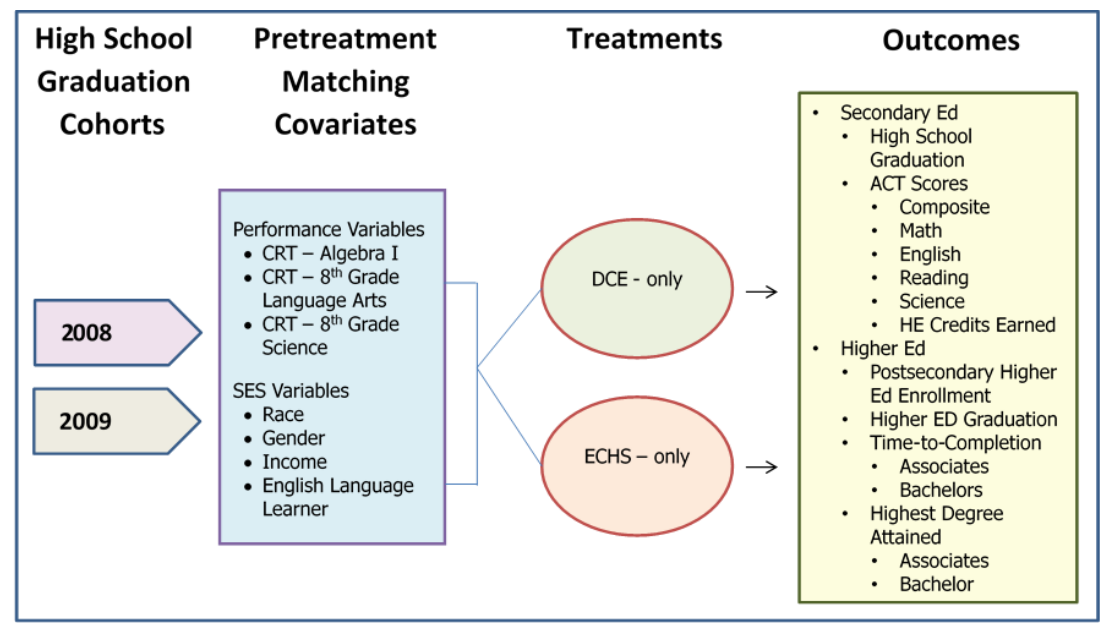

Figure 10. PSM pre-treatment, treatment and outcome model

\subsection{Receiver Operating Characteristic (ROC) Analysis}

As outcomes based on PSM methods may vary depending on the selection of pretreatment variables and adjustment mechanisms internal to the methodology's models (nearest neighbor, caliper, and tolerance form (Note 13)), Receiver Operating Characteristic (ROC) Analysis is used in this study to identify and employ an accurate model given the available variables and possible adjustments. ROC analysis quantifies the accuracy of diagnostic tests or other evaluation modalities used to discriminate between two states or conditions, allowing the discriminatory accuracy of a diagnostic test to be measured by its ability to correctly classify known subjects (Eng, 2005; Fawcett, 2006; Metz, 1978). The optimal model among these choices isn't necessarily the model offering the largest coefficients, but the model yielding the most accurate outcomes.

ROC analysis is built on a framework in which a cluster of analyses is examined with the cluster's estimated outcomes being compared to the observed outcomes such that sensitivity and specificity values between zero (0) and one (1) may be assigned each cluster (Eng, 2005; Fawcett, 2006; Metz, 1978). Sensitivity, also referred to as the true positive rate - the ratio of true positives to total positives, and specificity is the ratio of true negatives to false positives plus true negatives. As false positives plus true positives equal one (1) or 100\%, specificity is also referred to as 1-false positive rate.

As PSM models are built around a treatment as a binary state with a binary outcome, ROC's use of sensitivity and specificity is well aligned with the analytical method. However, where continuous outcome variables are present the potential outcomes must be separated into binary groups, otherwise the application of ROC analysis isn't feasible (Eng, 2005; Fawcett, 1978; Metz, 1978).

Visualizing the application of ROC analysis for a particular model based on variations in model specification is shown in Figure 11, using the effects of Dual-Credit Enrollment (DCE) on K12 Graduation (K12 GRAD) for the 2008 high school graduation cohort with variations in pretreatment variables and Nearest Neighbor matches. As this particular model, one of many in this study, may be used to examine student outcomes based on a combination of eight pretreatment variables and three Nearest Neighbor match levels, there are nearly 241,000 possible models available, each separable into clusters resulting in separate combinations of sensitivity and specificity, with each combination forming a point on a ROC curve and yielding an area under the curve (AUC). 


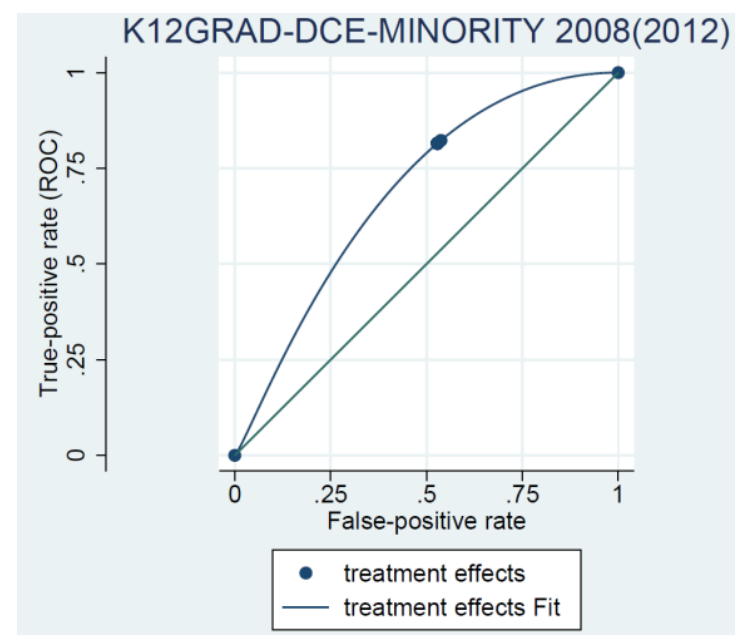

Figure 11. ROC Curve K12 GRAD DCE 2008

For this study we include three high school performance variables (CRT scores for Science, Language Arts, and Algebra I) in each model variation and select combinations of Gender, Minority, Income, Mobile, ELL and Nearest Neighbor match in 10 model variations (Appendix A (Note 14)) resulting in different values for each area under the curve (AUC) and yielding separate ROC curves for each model such that a set of ROC curves may be plotted revealing the optimal model - the model with greatest AUC.

\section{Underrepresented Student Outcomes}

In this section, we consider the secondary and higher education outcomes of a variety of student groups differentiated by treatment but also compare the outcomes of treated members of each group and those of the general student population. For each treatment, DCE and ECHS, the control group (TRAD) is those students who did not participate in any form of dual credit enrollment.

The reported outcomes for the 2008 and 2009 high school graduation cohorts are averaged, though each individual cohort's results are available in Appendix B (Note 15), including coefficients, standard errors, z-scores, p-values and confidence intervals for each outcome measured for each cohort, student sub-group, and treatment combination based on PSM average treatment effects of the treated. Appendix A reports the ROC analysis similarly and reports the area under the curve (AUC) for each outcome, student group, and treatment combination. The following includes the PSM estimation coefficients for many of the estimated outcomes in this study and only specifies a model's ROC AUC in the event the PSM analytic lacks statistical significance $(P>|z|$ exceeding 0.10) (Note 16).

The differentiated student groups include female, male, minority, low income, English language learner, minority male, minority female, low income male and low income females student populations. Including males as a group amongst underrepresented students may be counter intuitive, but as the data shows, males are "underrepresented" in higher education compared to females generally. Males also fare poorly compared to females in many of the measured outcomes and the treatment effects for this group are often higher than for other groups. As such, both males and females are included in this analysis.

Both DCE and ECHS program participant (treatments) reflect improved high school graduation experience compared to TRAD, but there is limited difference in the outcomes of the two programs. Treatment participation among the general student population reflects improved probability of high school (K12) graduation of $20.9 \%$ and $22.4 \%$, respectively. While each of the underrepresented student groups reflect yet greater improvements, low income and minority males show the greatest improvement; $32.8 \%$ and $36.7 \%$ for minority males and $30.9 \%$ and $35.5 \%$ for low income males. The graduation experience of low income females is also much improved, but by a lesser margin; $29.1 \%$ and $30.4 \%$ (Figure 12 ). 


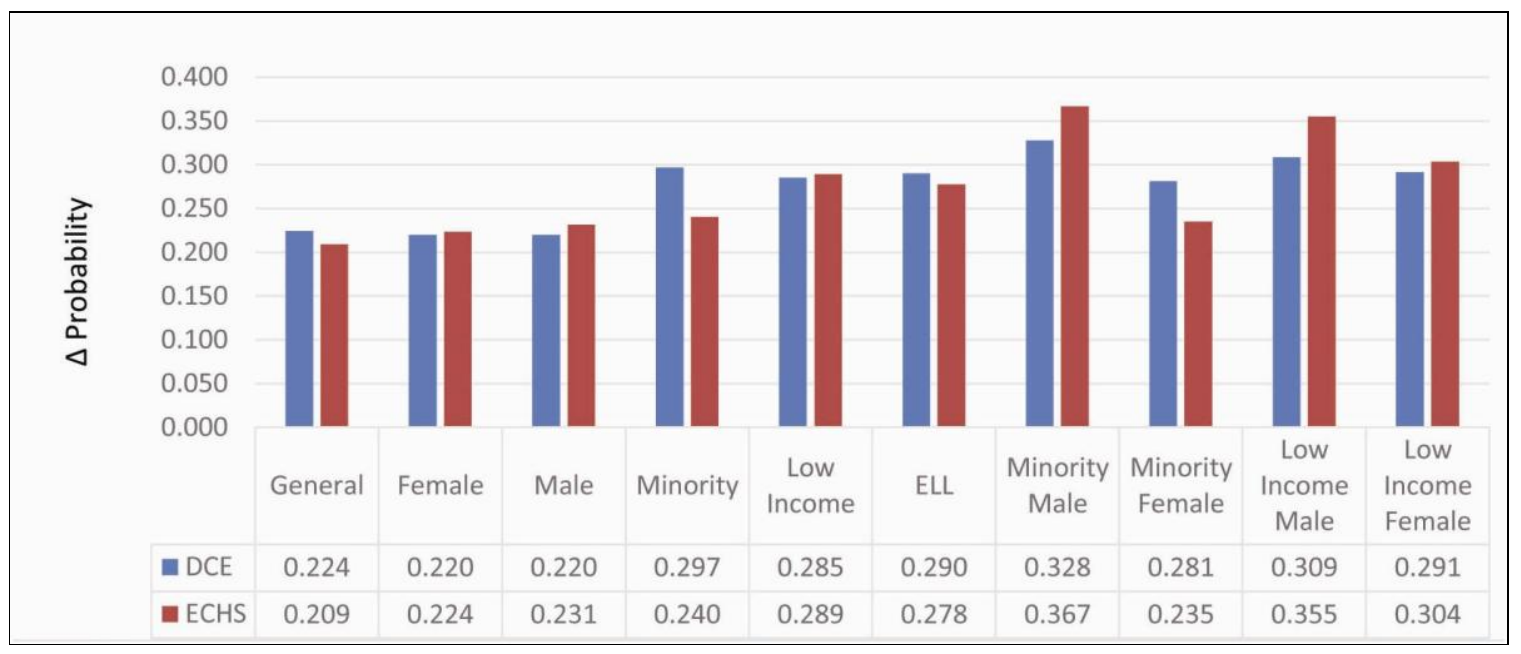

Figure 12. Concurrent enrollment credits earned

While DCE and ECHS effects on ACT scores for Math, Reading, English, and Science were estimated for underrepresented students, only ACT Composite scores are included in this section (Appendix B). While the average treatment effect on the treated is only marginally positive for the general student population with score changes of 0.25 and 0.35 respectively (out of a total possible score of 36); males, minority students, and low income males and females received the strongest score improvements among the student groups. Though fully one half of the 40 PSM estimates for this outcome experienced problems with statistical significance, the lowest ROC AUC for those problematic estimates was 0.616 (ECHS Female) and all other AUC's were between 0.729 and 0.827 .

The effects of DCE on dual course credits varied little among the student groups (5.14\%), though the effects of ECHS varied by as much as $30 \%$ amongst the underrepresented student groups. The differentiated treatments clearly indicate higher level of credit accumulation among ECHS participants. The range of credit accumulation amongst the DCE participants in the differentiated student groups is 5.64 to 5.93, while the ECHS participant range is 9.09 to 11.78 (Figure 13). The high dual course credit earned level amongst DCE participants is observed for Low Income Males at 5.93, while the high ECHS level is seen in the ELL student group at 11.78. The ELL group also had the lowest credit accumulation level amongst DCE participants, suggesting potentially higher English language literacy amongst ECHS students in this group.

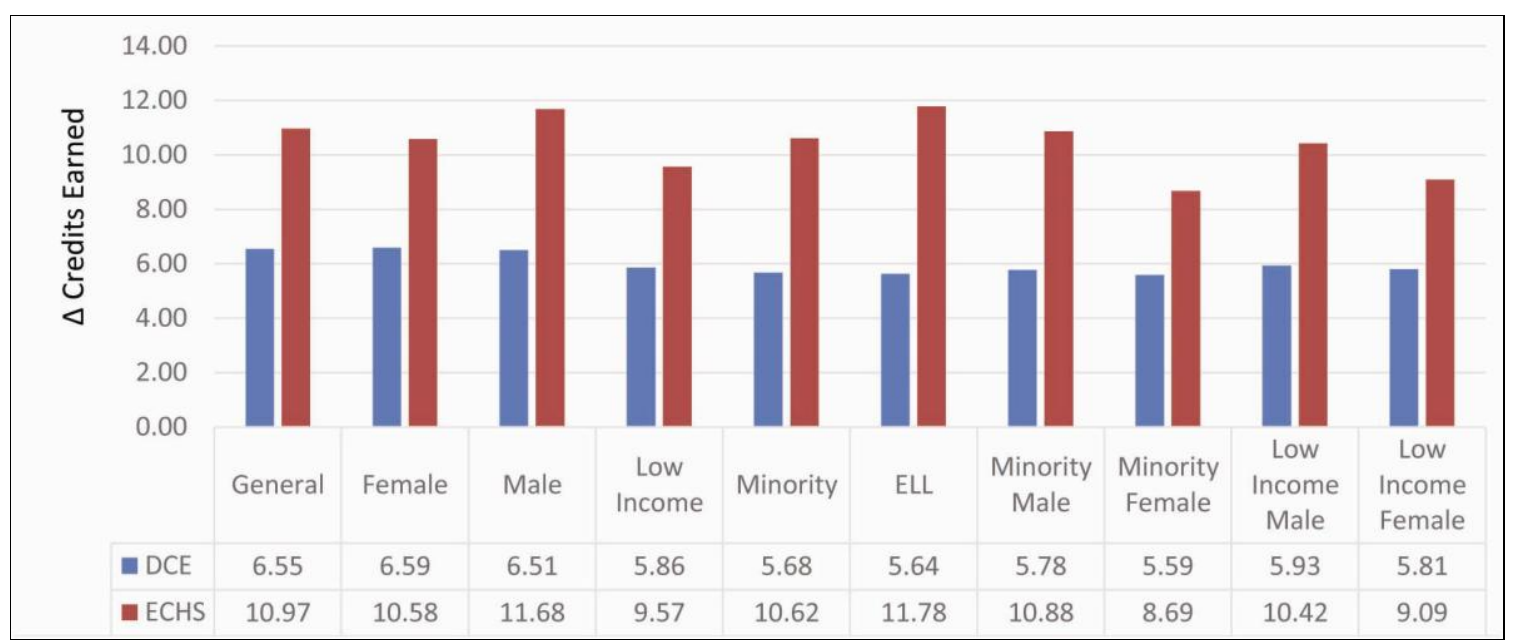

Figure 13. Post secondary higher education enrollment - USHE

Post-secondary higher education enrollment in Utah public higher education (USHE) is of particular import to this study and the PSM estimates show improved probabilities of enrolling in Utah public higher education 
among minority and low income student groups of between $26.5 \%$ and $34.5 \%$ for DCE participants and $30.2 \%$ and $40.1 \%$ for ECHS students (Figure 14). This compares to $27.8 \%$ and $36 \%$ for general population students and differs only slightly when the analysis extends to all post-secondary higher education enrollments (Figure 5.4).

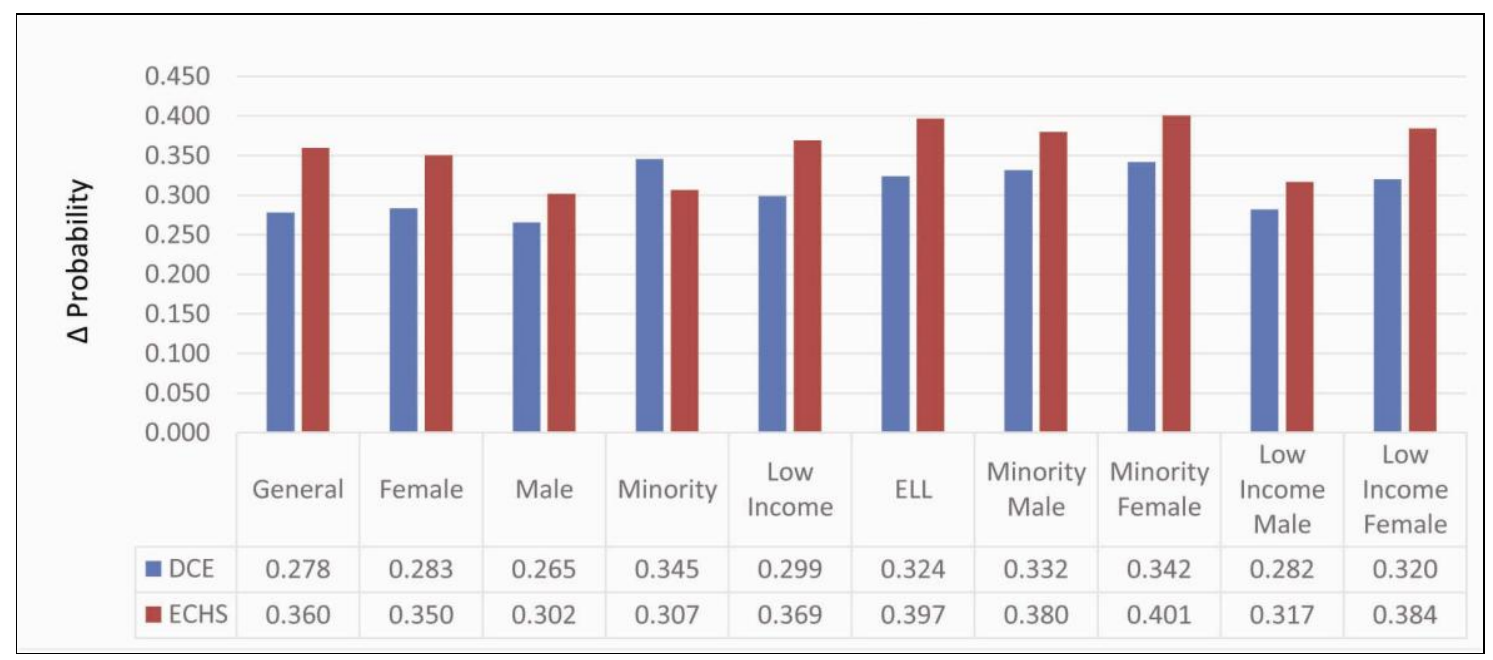

Figure 14. Post secondary higher education enrollment - All

Higher education graduation includes the earning of an Associate's degree or higher in this study. Utah Higher Education graduation outcomes reflective of DCE treatment participation was relatively low for the general student population and each of the minority and low income student groups, with probability of higher education graduation improvements in the USHE system ranging from $2.2 \%$ for minority males to $7.5 \%$ for females; an improvement of $6.7 \%$ for the general student population.

ECHS participants present an entirely different picture with the lowest probability improvement within minority females at $16.7 \%$ and the highest improvement amongst males of $44.7 \%$; the general student population was $41.5 \%$. Like post-secondary higher education outcomes, there was little difference between improved graduation experience within Utah public higher education (Figure 15) and higher education generally (Figure 16). The structure of ECHS programs in Utah account for much of the probability improvement as ECHS participants accumulate significant higher education credits, leading to Associate's degree attainment rates of as high as $72 \%$ amongst Utah's six Early College High Schools.

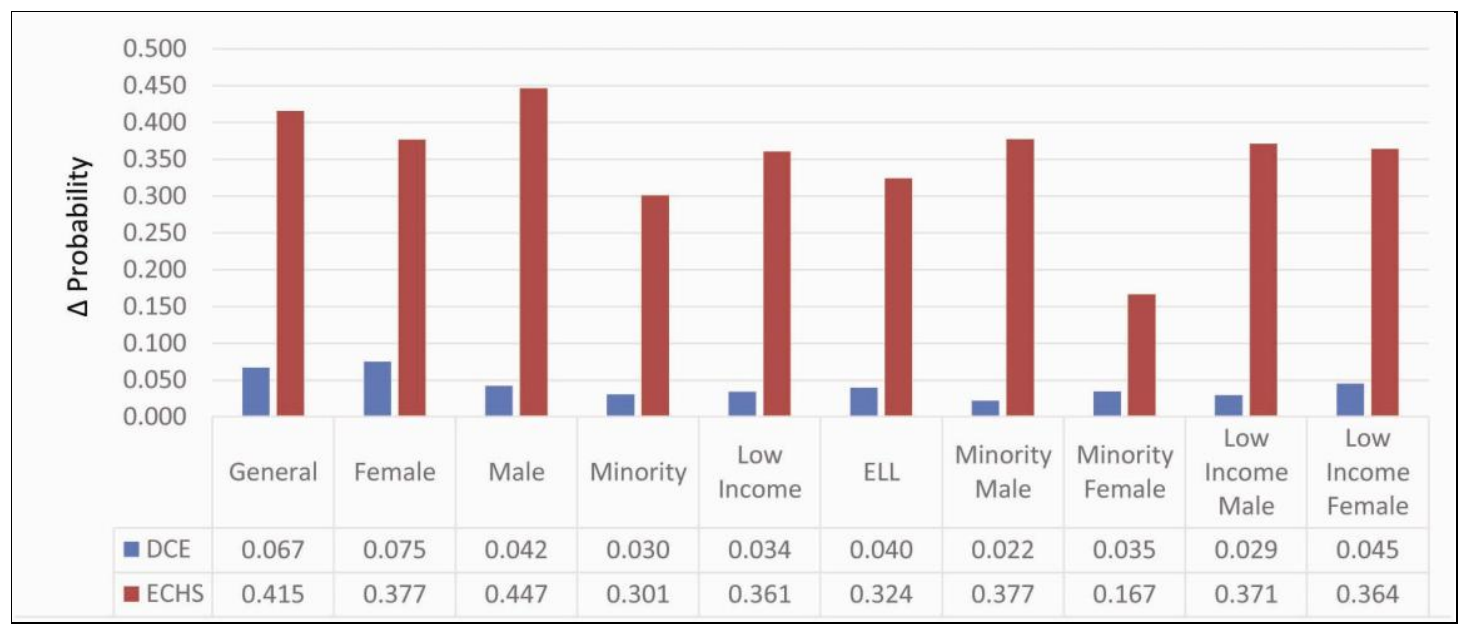

Figure 15. Higher education graduation - USHE 


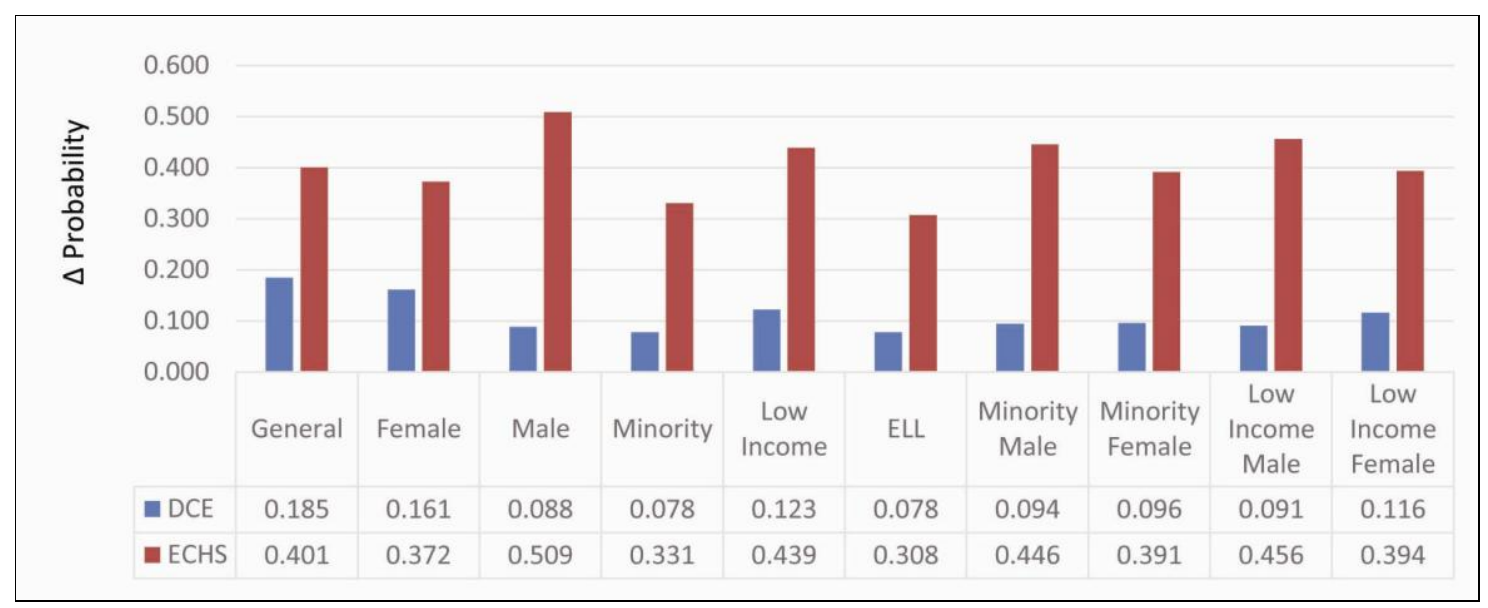

Figure 16. Higher education graduation

Higher education time-to-completion in this study examines Associate's and Bachelor's degrees earned through all of higher education. The reported coefficients are the decrease in number of days-to-completion resulting from DCE and ECHS participation. While these are reflected as positive values in the presented figures (Figure 17 and 18) they are reported as negative values in the PSM outcomes in Appendix B.

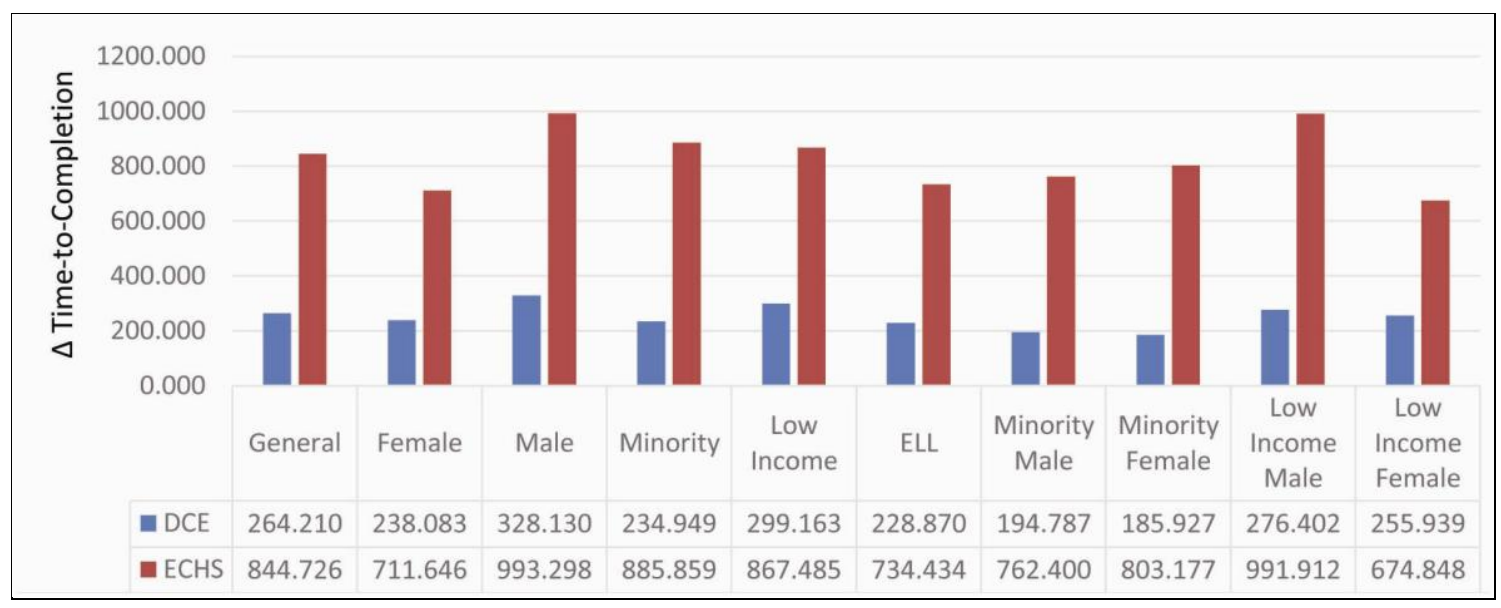

Figure 17. Higher education time-to-completion: Associate's

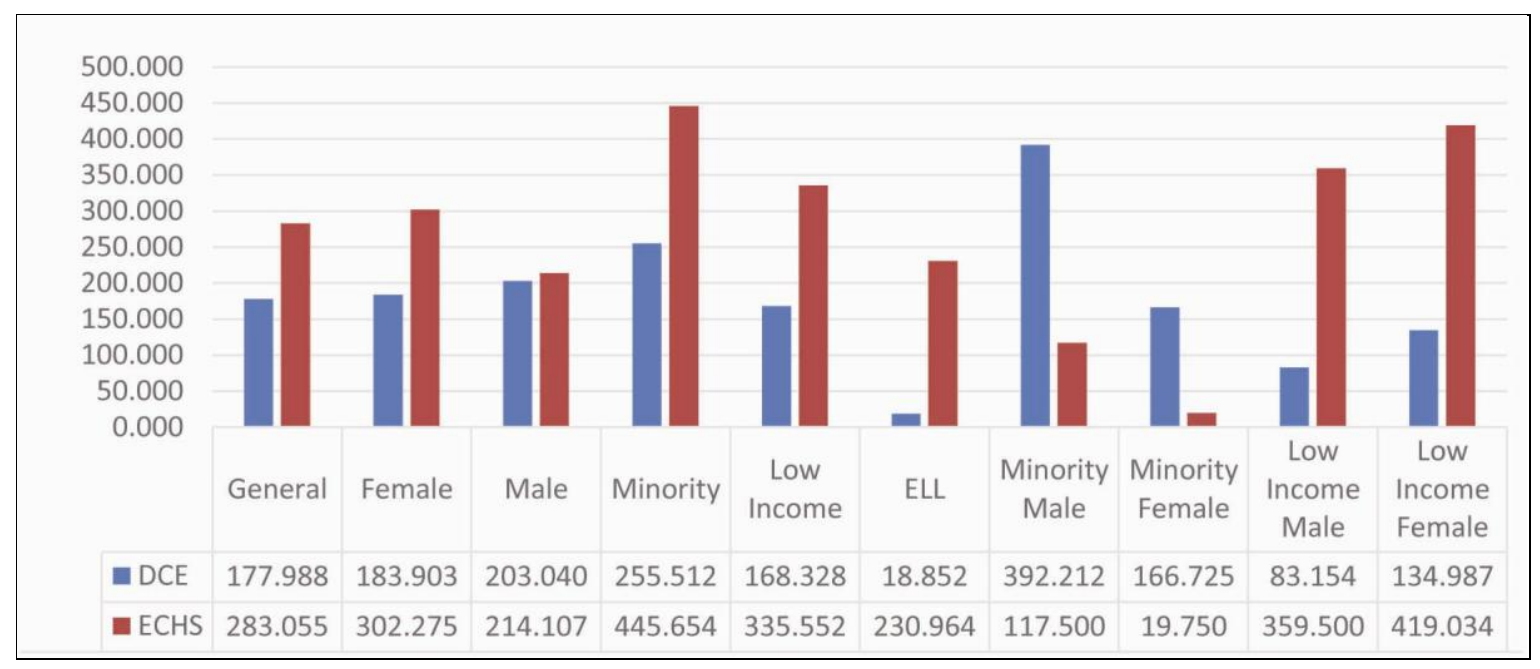

Figure 18. Higher education time-to-completion: Bachelor's 
Amongst DCE participants who earned an Associate's degree during the study period, males and low income males experienced the greatest improvements of 328 and 276 fewer days to completion, but even the lowest levels of improvement, found in minority males, reflect improvements of more than 194 days. ECHS participants experienced significantly greater gains, once again owing to program structure, as males and low income males experience improvements of 993 and 992 days respectively. The least level of improvement for ECHS participants was found among low income females at 675 days. The only problem with statistical significance among these estimates was found for minority females, for which the ROC AUC is 0.9 , reflecting a highly accurate model for this estimation.

While higher education time-to-completion for those earning Bachelor's degrees reflects improvements for each student group, there are a few significance problems that correlate with low ROC AUC values. There were sufficiently few English language learners amongst ECHS participants such that an AUC could not be calculated and statistical significance is below any plausible level. The AUC for minority females was only 0.5371 , a level just barely above that which might be obtained via random guessing. As such, while the outcomes for these groups are reported, they are not reliable. Amongst those with reliable outcomes, minority students and low income females report the greatest gains of 419 and 446 days respectively, well above the gains of the general student population. Also of interest is a comparison of the gains experienced for those earning Associate's and Bachelor's degrees. Much of the gains for Associate's degree earners dissipate when it comes to earning a Bachelor's degree.

PSM estimates for higher education graduation for Associate's degrees reflect the greatest improvement in probability of degree attainment among minority males and minority females (Figure 19). DCE participants experienced improvements of $10.6 \%$ and $8.5 \%$ respectively, while ECHS participants saw gains of $18.3 \%$ and $19 \%$. General student population gains were $2.3 \%$ for DCE students and $4.1 \%$ for ECHS students and the gains experienced by each of the remaining subgroups exceeded those of the general student population by an average of $3.6 \%$ and $4.6 \%$ for DCE and ECHS participants, respectively.

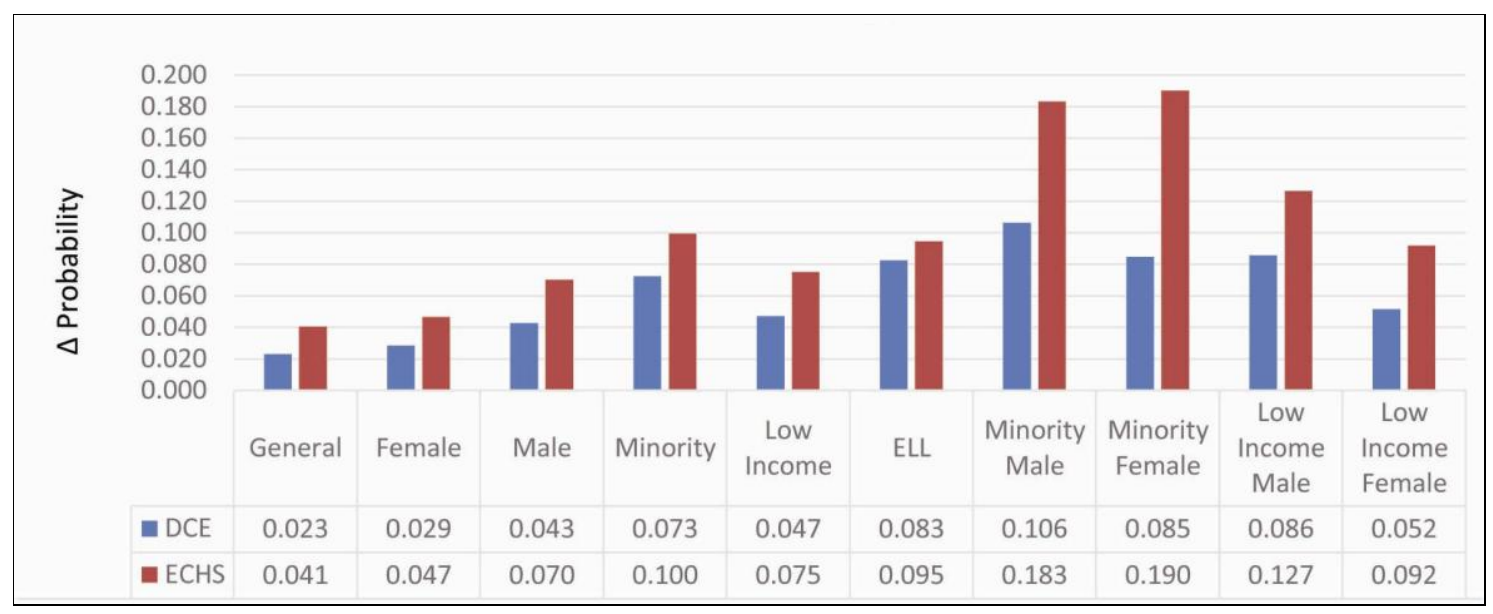

Figure 19. Higher education graduation: Associates

Eight of the forty PSM estimates for this outcome experienced problems of statistical significance, though the average ROC AUC was 0.7425 with a low of 0.6459 and high of 0.8182 , suggesting the models were reasonably well specified and of sufficient strength to be reliable. The PSM and ROC outcomes for Higher Education Graduation: Bachelor's suffered extensively from such levels of statistical significance that it renders reporting the outcomes irresponsible, as such, these outcomes can be found in Appendix B, but are not discussed here.

\section{Conclusion and Policy Considerations}

The success and growth of dual-credit enrollment programs to date have brought them into sharp focus for policy makers, but until recently the data to objectively assess their relative levels of success has been limited (Taylor, 2013; Smith, 2007; Swanson, 2008). With the release of the Utah Education Longitudinal Data, and similar data sets like it in other states, we're only now beginning to separate the effects of DCE from those of ECHS with respect to high school and higher education outcomes. An analysis of labor market outcomes, which many hold as the true test of these programs, remains at least several years away as the first high school graduates from 
these differentiated programs only recently began to graduate from higher education.

Clearly, student success is a function of numerous inputs, of which formal education comprises an important part. Influential household level attributes such as parental and sibling education, household composition, social networks and student intellect form what we might refer to as household endowments with respect to education, but these neither negate nor discount the import of education policy with respect to student success (Bragg, Kim, \& Rubin, 2005). The available Utah data includes variables specifically related to education policy with only a limited number of demographic and socio-economic variables to aid us in considering the effects of the students' household endowments on high school and higher education outcomes. However, as we examine outcomes for underrepresented students, these variables, combined with those which measure specific outcomes, are sufficiently important to render the analysis meaningful, if not perfect (Bailey \& Kienzel, 2006; Taylor, 2013).

Students from an increasingly wide set of income and race backgrounds are populating the nation's high schools, colleges and universities (Kodrzcki, 2002). The male gender bias once pervasive in higher education participation, completion and degree attainment now appears to have shifted towards a decidedly female bias in all but select courses of study. These changes are becoming especially important to Utah policy makers, but the reality that transition from high school to higher education remains difficult for low income, minority and English language learner students is persistent. This difficulty ultimately equates to lesser rates of high school graduation, and higher education enrollment, completion and degree attainment for these populations compared to their peers and ultimately results in lower levels of productivity and income in the labor markets. Policy aimed at effecting household endowments is difficult to plan and execute, and often takes many years for benefits to be realized (Orr, 2002; Rogers, 1992). Though it may not be immediately obvious, policy directed towards high school and higher education for a given generation results in household endowment changes in future generations. As such, public education policy offering marginal improvement may have long lasting and multiplicative socio-economic effects; this is especially true of those policies yielding important gains for underrepresented students.

This study has shown that dual-credit enrollment programs yield varying levels of improvements in the probability of female, male minority, low income, and English language learner students high school graduation, post-secondary higher education enrollment, and higher education graduation and degree attainment. These positive correlations suggest these programs, when analyzed as treatments on student populations, aid in improving the student condition and preparing students for their next steps into society and the markets. Where DCE and ECHS participation improve underrepresented students' probability of high school graduation by an average of $27.4 \%$ and improve post-secondary higher education enrollment by $30.7 \%$ and $35.7 \%$ respectively, they set the stage for improved rates of higher education completion and degree attainment. DCE's relationship between program participation and Utah public higher education graduation averaged $4.5 \%$ for the targeted high school graduation cohorts and while this may seem to be a small marginal effect, the impact on the 90,642 student in these cohorts could result in nearly 4,100 additional higher education degree holders in the state. Similar measures for Early College High School students, with gains in the probability of Utah public higher education graduation of $35 \%$, may yield multiples of that value.

Similarly, the effects of dual-credit enrollment program participation on dual course credits earned and higher education time-to-completion are clear. Without DCE and ECHS programs the opportunity to earn these higher education credits and decrease time-to-higher education completion simply would not exist. The gains available through Dual-Credit Enrollment are consistently lower for low income and minority student groups than they are for their general student population counterparts, though these gains clearly separate program participants from their peers and increase the likelihood of post-secondary higher education enrollment and higher education degree attainment.

ECHS participation yields yet greater gains in dual course credits earned for English language learners than those in the general student population, regardless of gender. However, not all students are interested in participating in dual-credit enrollment programs, and were any given state to attempt to include all high school students in either of these programs the effective gains may diminish. But for those who do participate, the gains may yield life changing benefits. As such, motivating greater student participation in these programs through strategic expansion of both DCE and ECHS offerings stands to yield important benefits to the state and student households. This is particularly relevant when it comes to the needs of underrepresented students, where gains in each of the measured areas are largely stronger for these student groups (Hoffman, 2003). That the express intent of dual-credit programs includes targeting underrepresented student participation is validated through these results, but the Utah case reflects much work to be done as these student groups continue to be underrepresented in such programs. While ECHS student demography is more closely aligned with that of the general student 
population than is that of DCE, just over $2 \%$ of the state's high school students participate in this program. While state and district level efforts to expand the accessibility of ECHS stand to yield important benefits, increased efforts to motivate underrepresented student group participation must be given a high priority.

While it may be difficult to measure the particular economic effects of most of the outcomes measured in this study, the economics of providing higher education credit hours during high school versus while enrolled in higher education is relatively straight forward, as may be the temporal benefit resulting from the decreased time-to-completion due to dual-credit enrollment programs (Hunt, 2007; Karp, Bailey, \& Hughes, 2005).

Funding for Utah's dual-credit courses is provided largely through funds allocated by the Utah State Office of Education (Note 17) based on student higher education credit hours earned with amounts differing for concurrent enrollment, early enrollment and advance placement courses. For the 2014 academic year ending June $30^{\text {th }}$, Utah public education allocated less than $\$ 6.9$ million for dual-credit enrollment out of more than $\$ 2.9$ billion provided those public high schools offering such courses; less than $0.24 \%$. When broken down by type of high school, the state's 2014 allocation memo shows that traditional high schools offering dual-credit courses were budgeted to receive $0.38 \%$ of their funds for the support of these students/courses, non-ECHS schools were allocated $0.21 \%$ and ECHS's were allocated $3.56 \%$ of their budget in support of dual-credit courses. The significant difference between ECHS and others reflects the mission and purpose of these schools with respect to the number of higher education credit hours their students are designed to accumulate.

Where dual-credit courses are offered through the traditional or charter high school that is not an early college high school, student households may be assessed fees as allowed by the Utah Administrative Rule. For those students enrolled in a traditional high school, policies regarding who pays the allowable fees differ by district, with student households being required to pay much or all of the allowable fees. Courses required for high school graduation taken through one of Utah's six ECHS's are provided without added cost to the student household; the high school's budget bearing the expense. Non-dual-credit enrollment college courses taken by ECHS students, which also fulfil high school course requirements and are necessary for high school graduation, such as some science or STEM courses, are paid for by the ECHS out of its state allocated revenues.

Where these courses are taken by ECHS students for the purpose of earning sufficient higher education course credits to receive an Associate's degree coincident with earning their high school diploma, the student household is often required to bear the higher education tuition expense as agreed upon by the ECHS and the affiliated college. Students who earn sufficient credits to receive an Associate's Degree often pay upwards of $\$ 1,000$ in higher education costs in order to do so, a modest expense compared with an average two-year in-state tuition cost of $\$ 8,640$ (Note 18) required by Utah's public colleges and universities for sufficient credit hours to earn an Associate's degree. Just as with most other forms of higher education, those households unable to afford the additional higher education expenditure find it may be financed by federal student loans or other student financial aid programs.

During the academic year 2009-2010, the State of Utah allocated \$6,165,271 for Advanced Placement and Concurrent Enrollment programs at the public high school level5, resulting in 194,614 higher education credits earned by 28,185 students; an average of 6.9 credit hours for each participating student at a cost of $\$ 218.74$ per student or $\$ 31.70$ per credit hour. Had these students enrolled in the same number of credit hours at Salt Lake Community College (Note 19) during the same year, the per unit cost based on a full-time-equivalence of 14 credit hours at a cost of $\$ 2,416$ per semester would have resulted in a combined cost to the state and household of $\$ 172.57$. The net effect of these students having the opportunity to earn higher education credit hours under dual-credit enrollment programs resulted in a combined state and household level cost savings of $\$ 140.87$ per credit hour for a total of $\$ 27,415,274.18$ (Note 20). Of this amount, households would have born $\$ 19,391,895$ (Note 21) in tuition expenses and the state would have born an additional $\$ 8,023,935$ (Note 22) over and above that which had already spent on these same students and credit hours at the high school level.

Low income and minority households, with fewer economic resources to expend on higher education, stand to experience greater gains from these savings than their better resourced counterparts (Bailey, Hughes, \& Karp, 2003; Brand \& Lerner, 2006). Concern over rising levels of student loan debt has increased in recent years as the household higher education costs have risen. As race and gender based income and wealth disparities remain persistent, the effects of such debt may be particularly troublesome with respect to these student populations. Decreases in household level higher education costs under dual-credit enrollment programs potentially reduces student loan debt levels giving rise to longer-term benefits as household discretionary income increases due to lower levels of debt servicing. These affordability effects may be contributing factors to the improved probabilities these student groups experience with respect to post-secondary higher education enrollment and 
higher education completion and degree attainment.

The benefits of reduced time-to-completion arising from dual-credit enrollment programs potentially include increased rates of labor force participation as students benefiting from these programs stand to enter the workforce at younger ages and with greater probabilities of increased levels of higher education completion and degree attainment (Johnstone \& Del Genio, 2001). This may be especially impactful for minority students, earning Bachelor's degrees with decreased time-to-completion of 255 and 445 days for DCE and ECHS respectively; for low income students, temporal savings are along the lines of 168 and 654 days. The present and future value of these improvements are a function of discount rates and employment rates, income levels and retirement ages of course, and as such may be difficult to quantify at the beginning of a student's career. However, the gains may offer important economy wide contributions through increased levels of household demand, local, state and federal tax revenues, and potential decreases in social support often required by underrepresented households.

The gains dual-credit enrollment participants experience in time-to-completion at the Associate's degree level appear to dissipate for those students earning Bachelor's degrees. From 299 and 867 days of improved time-to-completion for an Associate's degree, low income student experience reflects declines of 131 and 213 days for DCE and ECHS, respectively. For those students who earn their Associate's degrees, a transfer degree in General Studies is the most commonly earned. These students tend to be 17-18 years of age and have little exposure to subject areas in which they may ultimately choose to major or plan a career, and as such the major selection for a four-year degree often includes falling back and taking courses that might have been taken in years one or two of their higher education experience or making course corrections during their third and fourth years. Depending on the college or university from which the students select to earn their Bachelor's degree, some of these students find sufficient differences in course requirements that certain course credits do not transfer, or transfer at a lower credit rate, resulting in the need to retake courses or simply taking more courses than otherwise expected. Yet other students lack the emotional maturity and perspective necessary to make long-term education decisions or simply take time away from higher education, voluntarily spending down some of the advantage gained (Speroni, 2010; Venezia, Kirst, \& Antonio, 2003). In any event, much of the temporal advantage gained through dual-credit enrollment participation is lost for many of these students, effectively decreasing though not eliminating, important benefits gained from these programs.

Perhaps the most enduring benefit of participation in dual-credit enrollment programs involves the household endowment effect with respect to education. We sometimes forget that gains from education policy often occur over decades and while they may also be reflected in the productivity of any given student or worker, their most meaningful impact may be experienced generations in the future. Our society's current focus on post-secondary or higher education completion is made possible by the high school movement of the early $20^{\text {th }}$ century, prior to which only higher performing or economically advantaged students participated in secondary education. Similarly, it wasn't until the latter part of the same century that higher education began to become accessible to the masses. The public policy resulting in these advancements in human capital investment not only set the stage for the golden age of capitalism, but also led to household level endowments motivating yet higher levels of investment for future generations. In similar fashion, as dual-credit enrollment programs, the roots of which may be found in the early 1970's, result in higher rates of educational participation and attainment, they set the stage for future generations of households with higher incomes, parents whose college degrees form expectations for their children, and young people with the preparation and perspective to reach for greater levels of innovation and productivity.

\section{Acknowledgements}

This study was made possible by the generous support and encouragement of Drs. Codrina Rada and Thomas Maloney of the University of Utah, Department of Economics, and the data analysts and staff of the Utah Data Alliance and its stakeholders: the Utah State Office of Education, Utah System of Higher Education, Utah College of Applied Technology, Utah Education Network, Utah Department of Workforce Services, and the Utah Education Policy Center.

\section{References}

Abadie, A., \& Imbens, G. W. (2012). Matching on the estimated propensity score. NBER Working Papers, (December 2012), 1-36.

Alliance for Excellent Education. (2009). Potential economic impacts of improved education on Utah. (2009, October). Alliance for Excellent Education. 
Alliance for Excellent Education. (2011a). Alliance for Excellent Education: The crisis and economic potential in America's education system. Alliance for Excellent Education.

Alliance for Excellent Education. (2011b). Education and the economy: Boosting state and local economies by improving high school graduation rates. Alliance for Excellent Education.

Alliance for Excellent Education. (2011c). Education and the economy: Boosting Utah's economy by improving graduation rates. Alliance for Excellent Education.

Alliance for Excellent Education. (2011d). Saving now and saving later. Alliance for Excellent Education.

Alliance for Excellent Education. (2011). State report card: Utah high schools. (2011, September). Alliance for Excellent Education.

Alliance for Excellent Education. (2012). Utah state card. Alliance for Excellent Education. Retrieved from http://all4ed.org/reports-factsheets/high-school-state-cards-utah/

An, B. (2009). The impact of dual enrollment on college performance and attainment (Published doctoral dissertation, University of Wisconsin-Madison, Madison, WI).

Austin, P. C. (2011). An introduction to propensity score matching methods for reducing the effects of confounding in observational studies. Multivariate Behavioral Research, 46, 399-424. http://dx.doi.org/10.1080/00273171.2011.568786

Bailey, T. (2007). Implications of educational inequality in a global economy. In C. R. Belfield, \& H. M. Levin (Eds.), The price we pay: Economic and social consequences of inadequate education (pp. 74-95). Washington DC: Brookings Institute.

Bailey, T., \& Karp, M. M. (2003). Promoting college access and success: A review of credit-based transition programs. Washington DC: US Department of Education, Office of Vocational and Adult Education.

Bailey, T., Hughes, K., \& Karp, M. M. (2003). Dual enrollment programs: Easing transitions from high school to college. Community College Research Center Brief, March, 1-4.

Berger, A., Turk-Bicaki, L., Garet, M., Song, M., Knudsen, J., Haxton, C., ... Stephan, J. (2013). Early college, early success. American Institutes for Research, (June 2013), 1-130.

Boswell, K. (2001). State policy and postsecondary enrollment options. New Directions for Community Colleges, 113(Spring), 1-10.

Bragg, D. D., Kim, E., \& Rubin, M. B. (2005). Academic pathways to college: Policies and practices of the fifty states to reach underserved students. Office of Community College Research Leadership, Department of Educational Organization and Leadership, University of Illinois at Urbana-Champaign.

Brand, B., \& Lerner, J. B. (2006). The college ladder: Linking secondary and postsecondary education for success for all students. American Youth Policy Forum, Washington DC.

Dehejia, R. H., \& Wahba, S. (2002). Propensity score matching methods for nonexperimental causal studies. The Review of Economics and Statistics, 84(1), 151-161. http://dx.doi.org/10.1162/003465302317331982

Edmunds, J. A., Berstein, L., Glennie, E., Willse, J., Ashavsky, N., Unlu, F., ... Dallas, A. (2010). Preparing students for college: The implementation and impact of the Early College High School. Peabody Journal of Education, 85, 348-364. http://dx.doi.org/10.1080/0161956X.2010.491702

Eide, E. R., \& Showalter, M. H. (2012). Methods matter: Improving causal inference in educational and social science research: A review article. Economics of Education Review, 31, 744-748. http://dx.doi.org/10.1016/j.econedurev.2012.05.010

Eng, J. (2005). Receiver operating characteristic analysis: A primer. Academic Radiology, Johns Hopkins University, 12(7), 909-916. http://dx.doi.org/10.1016/j.acra.2005.04.005

Fawcett, T. (2006). An introduction to ROC analysis. Pattern Recognition Letters, 27, 861-974. http://dx.doi.org/10.1016/j.patrec.2005.10.010

Fincher-Ford, M. (1996). High school students earning college credit: A guide to creating dual credit programs. Corwin Press, Inc.

Greenberg, A. R. (1988). Concurrent enrollment programs: College credit for high school students. Fastback 284, Phi Delta Kappa Educational Foundation.

Harnish, D., \& Lynch, R. L. (2005). Secondary to postsecondary technical education transitions: An exploratory 
study of dual enrollment in Georgia. Career and Technical Education Research, 30(3), 169-188. http://dx.doi.org/10.5328/CTER30.3.169

Heckman, J. J., \& LaFontaine, P. A. (2010). The American high school graduation rate: Trends and levels. The Review of Economics and Statistics, 92(2), 244-262. http://dx.doi.org/10.1162/rest.2010.12366

Hoffman, N. (2003). College credit in high school: Increasing postsecondary credential rates of underrepresented students. Change, 35(4), 42-48. http://dx.doi.org/10.1080/00091380309604110

Holland, P. W. (1986). Statistics and causal inference. Journal of the American Statistical Association, 81(396), 945-960. http://dx.doi.org/10.1080/01621459.1986.10478354

Hunt, E. L. (2007). Dual funding for dual enrollment: An inducement or an impediment? Community College Journal of Research and Practice, 31, 863-881. http://dx.doi.org/10.1080/10668920600857255

Johnstone, B. D., \& Del Genio, B. (2001). College level learning in high school: Purposes, policies and practical implications. The Academy in Transition, Association of American Colleges and Universities, Washington DC.

Karp, M. M., \& Hughes, K. L. (2008). Supporting college transitions through collaborative programming: A conceptual model for guiding policy. The Teachers College Record, 110(4), 838-866.

Karp, M. M., Bailey, T. R., \& Hughes, K. L. (2005). State dual enrollment policies: Addressing access and quality. Community College Research Center Brief, 26, 1-4.

Karp, M. M., Calcagno, J. C., Hughes, K. L., Jeong, D. W., \& Bailey, T. R. (2007). The postsecondary achievements of participants in dual enrollment: An analysis of outcomes in two states. Community College Research Center, Teacher's College, Columbia University, 1-83.

Kim, J., \& Bragg, D. (2008). The impact of dual and articulated credit on college readiness and retention in four community colleges. Career and Technical Education Research, 33(2), 133-158. http://dx.doi.org/10.5328/CTER33.2.133

Kirst, M. W., \& Venezia, A. (2006, March 10). What states must do. Retrieved from http://chronicle.com/weekly/v52/i27/27b03601.htm

Kleiner, B., \& Lewis, L. (April 2005). Dual enrollment of high school students at postsecondary institutions 2002-2003. National Center for Education Statistics, US Department of Education, NCES 2005-008.

Kodrzcki, Y. K. (2002). Educational attainment as a constraint on economic growth and social progress. Education in the Twenty-first Century: Meeting the Challenges of a Changing World. Conference proceedings of the Federal Reserve Bank of Boston's 47th Economic Conference, June.

Lieberman, J. E. (2004). The Early College High School concept: Requisites for success. The Early College High School Initiative, 1-6.

Martinez, M., \& Bray, J. (2002). All over the map: State policies to improve the high school. The Institute of Educational Leadership, Washington DC.

McKinsey, \& Company. (2009, April). The economic impact of the achievement gap in America's schools. Retrieved April 16, 2015, from http://www.mckinsey.com/App_Media/Images/Page_Images/Offices/SocialSector/PDF/achievement_gap_r eport.pdf

Metz, C. E. (1978). Basic principles of ROC analysis. Seminars in Nuclear Medicine, VII(4), 283-298. http://dx.doi.org/10.1016/S0001-2998(78)80014-2

Morgan, S. L., \& Winship, C. (2007). Counterfactuals and causal inference: Methods and principles for social science research. New York, NY: Cambridge University Press. http://dx.doi.org/10.1017/CBO9780511804564

Murnane, R. J., \& Willett, J. B. (2011). Methods matter: Improving causal inference in educational and social science research. New York, NY: Oxford University Press.

National Center for Education Statistics. (2013). The condition of education 2013. Washington DC: National Center for Education Statistics.

National Commission on the High School Senior Year. (2001). Raising our sites: No high school senior left behind. Princeton, NJ: Woodrow Wilson National Fellowship Foundation. 
Ongaga, K. O. (2010). Students' learning experiences in Early College High School. Peabody Journal of Education, 85, 375-388. http://dx.doi.org/10.1080/0161956X.2010.491708

Orr, M. T. (2002). Dual enrollment: Developments, trends and impacts. Presentation to the Community College Research Center, Teachers College, Columbia University, New York, New York.

Peikes, D. N., Moreno, L., \& Orzol, S. (2012). Propensity score matching. The American Statesman, 63(2), 222-231. http://dx.doi.org/10.11198/00031313008X332016

Rogers, K. B., \& Kimpson, R. D. (1992). Acceleration: What we do vs. what we know. Educational Leadership, $50,58-61$.

Rosenbaum, P. R., \& Rubin, D. B. (1983). The Central Role of the Propensity Score in Observational Studies for Causal Effects. Biometrica, 70(1), 41-55. http://dx.doi.org/10.1093/biomet/70.1.41

Rosenbaum, P. R., \& Rubin, D. B. (1984). Reducing bias in observational studies using sub-classification on the propensity score. Journal of the American Statistical Association, 79, 516-524. http://dx.doi.org/10.1080/01621459.1984.10478078

Rosenbaum, P. R., \& Rubin, D. B. (1985). Constructing a control group using multivariate matched sampling methods that incorporate the propensity score. The American Statistician, 39(1), 33-38.

Schneider, B., Carnoy, M., Kilpatrick, J., Schmidt, W. H., \& Shavelson, R. J. (2007). Estimating causal effects using experimental and observational designs, Report from the Governing Board of the American Educational Research Association Grants Program. Washington DC: American Educational Research Association.

Scott, M., Bailey, T., \& Kienzl, G. (2006). Relative success? Determinants of college graduation rates in public

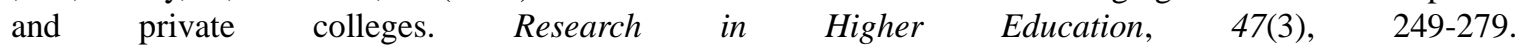
http://dx.doi.org/10.1007/s11162-005-9388-y

Shadish, W., Cook, T. D., \& Campbell, D. T. (2002). Experimental and quasi-experimental designs for generalized causal inference. Boston, MA: Houghton Mifflin Company.

Smith, D. (2007). Why expand dual credit programs. Community College Journal of Research and Practice, 31, 371-387. http://dx.doi.org/10.1080/10668920600932884

Speroni, C. (2010). High school dual enrollment programs: Are we fast tracking students too fast? Association for Institutional Research Forum, Chicago, IL, April 30, 2010, pp. 1-31.

Speroni, C. (2011). Determinants of students' success: The role of advanced placement and dual credit enrollment programs. National Center for Postsecondary Research, Teachers College, Columbia University.

Struhl, B., \& Vargas, J. (2012). Taking college courses in high school: A strategy for students' success: The outcomes of dual enrollment in Texas. Jobs for the Future, Retrieved from http://www.jff.org/sites/default/files/TakingCollegeCourses_101712.pdf

Swanson, J. L. (2008). An analysis of the impact of high school dual enrollment course participation on postsecondary academic success, persistence, and degree completion (Unpublished doctoral dissertation). Graduate College of the University of Iowa, Iowa City, IA.

Taylor, J. (2013). Community College Dual Credit: Differential Participation and Differential Impacts on College Access and Completion (Unpublished doctoral dissertation). University of Illinois at Urbana-Champaign, Champaign, IL.

US Department of Education. (2008). Four-year cohort graduation rates. Retrieved from https://www.google.com/search?q=US+department+of+education+four-year+cohort+graduation+rates\&ie= utf-8\&oe=utf-8\#q=US+department+of+education+four-year+cohort+graduation+rates +2008

USOE. (2013). Utah State Office of Education Yearbook 2013. Utah State Office of Education, Comp. Salt Lake City, UT: Utah State Office of Education.

Utah State Office of Education, Comp. (2014a). Utah Administrative Rule R277-713. Concurrent Enrollment of High School Students in College Courses, H.R. R277-713, 2014 Leg. (Utah 2014).

Utah State Office of Education, Comp. (2014b). Utah State Office of Education (USOE) revenue by district-LEA. Salt Lake City, UT: Utah State Office of Education.

Utah System of Higher Education Data Book. (2010). Summary of concurrent enrollment data (Utah System of Higher Education, Comp.). (2010). Salt Lake City, UT: Utah System of Higher Education. Retrieved from 
http://higheredutah.org/wp-content/uploads/2013/05/rd_2010_databook.pdf

Utah System of Higher Education Data Book. (2011). Cost Study, Tab I, p. 31. (Utah System of Higher Education, Comp.). Salt Lake City, UT: Utah System of Higher Education. Retrieved from http://higheredutah.org/wp-content/uploads/2013/05/rd_2011_databook.pdf

Vargas, J. (2013). The economic payoff for closing the college-readiness and completion gaps. Early College Designs, Jobs for the Future.

Venezia, A., Kirst, M. W., \& Antonio, A. L. (2003). Betraying the college dream: How disconnected K-12 and postsecondary education systems undermine student aspirations. US Department of Education.

Welsh, J., Brake, N., \& Choi, N. (2005). Student participation and performance in dual-credit courses in a reform environment. Community College Journal of Research and Practice, 29, 199-205. http://dx.doi.org/10.1080/10668920590901158

\section{Notes}

Note 1. Note the differentiation of the terms Dual-Credit Enrollment (DCE) and dual-credit enrollment. The term Dual-Credit Enrollment is used in this study to denote those students who participated in dual-credit courses providing both secondary and higher education course credit while enrolled in a traditional public high school. This is differentiated from dual-credit enrollment, which simply denotes those students who participated in any type of dual-credit course programs, either Dual-Credit Enrollment or Early College High School, while enrolled in public high school.

Note 2. In this study the term underrepresented includes groups of students not necessarily considered "underrepresented" throughout economics, education and social sciences literature. In this case underrepresented include differentiation of students into male, female, minority, low income, English language learners, minority male, minority female, low income male, and low income female subgroups.

Note 3. The Utah Education Policy Center (UEPC) is an independent, nonpartisan University of Utah research center in the College of Education that bridges research, policy, and practice for Utah public schools and higher education (www.uepc.utah.edu). The center houses the Utah Data Alliance and other research and policy based projects.

Note 4. Data for this research was accessible through Utah's state longitudinal data system database administered by the Utah Data Alliance (UDA) which includes data supplied by UDA partners and the StudentTracker service from the National Student Clearinghouse. This research including the methods, results, and conclusions neither necessarily reflect the views nor are endorsed by the UDA partners. All errors are the responsibility of the author.

Note 5. Utah Senate Bill 0034 (March 2014) provided ongoing funding for the Utah Data Alliance and Utah Education Policy Center http://le.utah.gov/ 2014/bills/static/SB0034.html

Note 6 . The term dual course credits in this study includes higher education credits earned through concurrent enrollment, early enrollment, and advanced placement courses.

Note 7. The 15 to Finish campaign encourages Utah's college students to graduate on time and save tuition. Most degrees in the Utah System of Higher Education require at least 120 credits to complete. If students want to finish their Associate's degree in two years or Bachelor's degree in four years, they need to take a minimum of 15 credit hours each semester. http://higheredutah.org/preparepay/15tofinish/ and http://15tofinishutah.com/\#resources

Note 8 . Prosperity 2020 is a public/private partnership with the goal of improving worker productivity and Utah's competitive position by motivating $60 \%$ of Utah's households to include at least one higher education degree holder as a head of household, http://prosperity2020.com/

Note 9. Utah's six Early College High Schools as of 6/30/2014: Academy for Math, Engineering and Science (AMES); Intech Collegiate High School; Itineris Early College High School; Northern Utah Academy for Math, Engineering and Science (NUAMES); Success Academy; and Utah County Academy of Sciences (UCAS).

Note 10. Charters for each of Utah's Early College High Schools are available through the Utah State Charter School Board, a unit within the Utah State Office of Education: http://www.schools.utah.gov/CURR/earlycollege/Early-College-High-School.aspx

Note 11. Data collected through the Utah Data Alliance longitudinal dataset for the Utah publish high school 
graduation cohorts of 2008 and 2009. Appendix C: Descriptive Statistics: www.richardhaskell.net/resources/Appendix+C+-+Descriptive+Statistics.pdf

Note 12. Many LDS males voluntarily postpone or take leave of higher education for a period of two years between the ages of 18-22 years old. Prior to the 2013-2014 academic year LDS females participation in such voluntary service began at age 21 and likely provides limited impact on the subject cohorts.

Note 13. Nearest Neighbor, Caliper, Tolerance and Form are adjustable specifications used in propensity score matching. Nearest Neighbor specifies the number of matches per observation, Caliper specifies the maximum distance at which two observations are a potential match. Tolerance specifies the minimum acceptable propensity score to be included. STATA's default parameters include Nearest Neighbor: 1; Caliper: all observations are potential matches regardless of how dissimilar they are; Tolerance: 1e-5; Form: Probit.

Note 14. Appendix A: Receiver Operating Characteristic (ROC) Analysis Matrix: www.richardhaskell.net/resources/Appendix+A+-+ROC+Analysis.pdf

Note 15. Appendix B: Propensity Score Matching (PSM) Analytic Tables: www.richardhaskell.net/resources/Appendix+B+-+PSM+Panels.pdf

Note 16. Of the 144 ROC estimations performed against the Underrepresented Student Population PSM models, only one indicated a weak model; that particular model considered the Early College High School's effect on an English Language learner's probability of earning an Associate's degree through Utah public higher education. Of 170 PSM estimations with respect to underrepresented students, 26.5\% (45) estimations experienced problems with statistical significance such that they were not found to be significant at any plausible level.

Note 17. Figures derived from Utah State Office of Education Allocation Memo, Minimum School Program Monthly Allotment for Fiscal Year 2014, Utah State Office of Education, pp. 1-352, April 21, 2014

Note 18. Annual tuition costs for full time students enrolled in one of the eight public colleges in the Utah System of Higher Education (USHE) average $\$ 4,320$ for in-state students, with a range from $\$ 2,830$ (Snow College) to $\$ 6,511$ (University of Utah). College Tuition Comparison Summary Table offered by College Tuition Compare: http://www.collegetuitioncompare.com/compare/tables/?state=UT\&type=Public

Note 19. Salt Lake Community College is the affiliated college for most dual-credit enrollment courses in the state of Utah and is the state's largest community college.

Note 20. Calculation of total cost savings: Based on per academic year FTE at 14 credit hours and two semesters per year, the per year total cost of lower division education at Salt Lake Community College for 2009-2010 equates to $\$ 4,832$ or $\$ 2,416$ per semester; $\$ 172.57$ per credit hour. Given the $\$ 31.70$ cost per credit hour to USOE, this results in a cost savings of $\$ 140.87$ per credit hour and totals $\$ 27,415,274.18$ when multiplied my 194,164 credit hours.

Note 21. Calculation of household level savings: Based on per semester full time tuition and fees at Salt Lake Community College for academic year 2009-2010 of $\$ 1,395$ and 14 credit hours per semester, the per credit hours cost equals $\$ 99.64$. Multiplied by 194,614 credit hours, this equals $\$ 19,391,895$.

Note 22. Calculation of state level savings: Based on the calculated cost savings of $\$ 140.87$ per credit less the household contribution of $\$ 99.64$ per credit, the state's additional cost of supporting these students as Salt Lake Community College students during the 2009-2010 academic year, over and above that which the state already contributed through supporting the cost of these students and credit hours at the high school level, equates to $\$ 41.23$. Multiplied over 194,614 units, the state savings equates to $\$ 8,023,935.22$.

\section{Copyrights}

Copyright for this article is retained by the author(s), with first publication rights granted to the journal.

This is an open-access article distributed under the terms and conditions of the Creative Commons Attribution license (http://creativecommons.org/licenses/by/3.0/). 